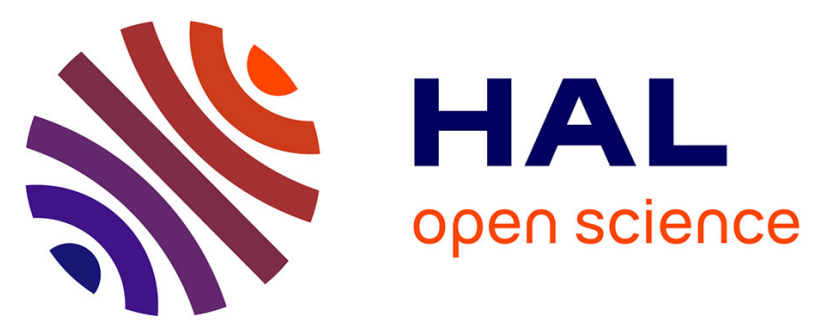

\title{
Main individual and product characteristics influencing in-mouth flavour release during eating masticated food products with different textures: mechanistic modelling and experimental validation
}

Marion M. Doyennette, Isabelle Deleris Déléris, Gilles Feron, Elisabeth E. Guichard, Isabelle I. Souchon, Ioan-Cristian I.-C. Trelea

\section{To cite this version:}

Marion M. Doyennette, Isabelle Deleris Déléris, Gilles Feron, Elisabeth E. Guichard, Isabelle I. Souchon, et al.. Main individual and product characteristics influencing in-mouth flavour release during eating masticated food products with different textures: mechanistic modelling and experimental validation. Journal of Theoretical Biology, 2014, 340, pp.209-21. 10.1016/j.jtbi.2013.09.005 . hal00939546

\author{
HAL Id: hal-00939546 \\ https://hal.science/hal-00939546
}

Submitted on 11 Jul 2017

HAL is a multi-disciplinary open access archive for the deposit and dissemination of scientific research documents, whether they are published or not. The documents may come from teaching and research institutions in France or abroad, or from public or private research centers.
L'archive ouverte pluridisciplinaire HAL, est destinée au dépôt et à la diffusion de documents scientifiques de niveau recherche, publiés ou non, émanant des établissements d'enseignement et de recherche français ou étrangers, des laboratoires publics ou privés. 
1 Main individual and product characteristics influencing in-mouth flavour release during eating masticated food products with different textures: mechanistic modelling and experimental validation

4

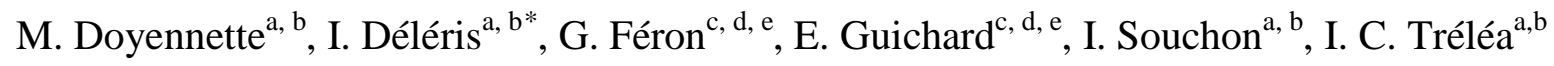
5 aINRA, UMR 0782, F-78850 Thiverval Grignon, France. isabelle.deleris@grignon.inra.fr; isabelle.souchon@grignon.inra.fr

b AgroParisTech, UMR 0782, F-78850 Thiverval Grignon, France. cristian.trelea@agroparistech.fr Dijon, France. gilles.feron@dijon.inra.fr; elisabeth.guichard@dijon.inra.fr

Running title: Modelling release from masticated foods 


\section{Highlights:}

- The developed model properly describes aroma release from masticated foods

- The mechanistic model includes both physiological and physical mechanisms.

- The most influent parameters for the intensity and the dynamics of the release were identified.

- The modelling approach highlighted aroma retention by lubricated mucosa. 


\section{Abstract}

17 A mechanistic model predicting flavour release during oral processing of masticated foods was developed. The description of main physiological steps (product mastication and swallowing) and physical mechanisms (mass transfer, product breakdown and dissolution) occurring while eating allowed satisfactory simulation of in vivo release profiles of ethyl propanoate and 2-nonanone, measured by Atmospheric Pressure Chemical Ionization Mass Spectrometry on ten representative subjects during the consumption of four cheeses with different textures. Model sensitivity analysis showed that the main parameters affecting release intensity were the product dissolution rate in the mouth, the mass transfer coefficient in the bolus, the air-bolus contact area in the mouth and the respiratory frequency. Parameters furthermore affecting release dynamics were the mastication phase duration, the velopharynx opening and the rate of saliva incorporation into the bolus. Specific retention of 2-nonanone on mucosa was assumed to explain aroma release kinetics and confirmed when gaseous samples were consumed.

Keywords: dynamic model; aroma compounds; food oral processing; physiology; mass transfer 


\section{Introduction}

34 The release of aroma compounds from food products during eating is a key step for their perception and ultimately for the acceptance of the product by the consumer. Food oral processing is complex [1] and flavour release induced by this processing depends on both the physiology and experience of subjects and on product properties. To identify what are these main properties explaining flavour release, it is necessary to develop an approach allowing the dissociation of mechanisms occurring during food oral processing. Mathematical modelling can help improving the understanding of the limiting mechanisms by pointing out the most important parameters related to the product and to the individual and allowing quantitative predictions of release dynamics. Therefore, models can help design the food products in a rational way, possibly targeted towards particular consumer groups such as young children, elderly or people with specific disorders.

The mechanistic modelling of aroma compound release during food consumption allows one to calculate, from known physical laws, the amount of aroma compounds transferred over time in each anatomical compartment involved during food oral processing (mouth, nasal cavity, pharynx).

The first mechanistic models have focused on predicting the release of aroma compounds from a two-phase emulsion (water, oil) in contact with gas [2]. They were based on physicochemical principles governing the release of volatile molecules from a food matrix: (i) the mass conservation of volatile compound, (ii) the mass transfer at the emulsion-gas interface (interfacial penetration theory), (iii) equilibrium properties at the emulsion-gas interface [3]. First-order chemical kinetics have also been included in some models to describe reversible interactions between aroma compounds and non-volatile compounds such as macromolecules [2]. However, these first models are not really representative of in vivo phenomena because the geometry of the system (surfaces and volumes) is assumed constant (which is not the case 
during food consumption) and they do not consider dynamic phenomena such as the dilution with salivary flow or the cyclic breathing of the subject. In addition, some of these models do not include any comparison with experimental data release [2].

Further development of these pioneering models has led to a better representation of in vivo conditions occurring during food consumption, by including notably parameters related to individual physiology, such as salivary flow, periodic breath, etc. [4, 5]. In addition, one of the major improvements in these models was to consider the aroma persistence phenomenon i.e. aroma release from bolus deposit covering the pharyngeal mucosa after swallowing. These models showed the relative roles of product and consumer characteristics and were validated against experimental data.

The first model including physiological data was proposed by Normand et al. [4] in the case of liquid products and highlighted two main release regimes: (i) release due to equilibrium batch extraction (only pertinent for few breaths after swallowing) and (ii) release from lubricated mucosa (persistence phenomena). In the case of semi-liquid food, the most comprehensive model to date is the one developed by Tréléa et al. [6] and further developed by Doyennette et al. [7] coupling aroma release in the mouth and in the pharynx.

Mechanistic models describing aroma release from masticated foods are far less available in the literature, mostly because of the difficulty to understand the complex mechanisms which are involved during the consumption of those foods. Compared to liquid products, mass transfer occurs through several interfaces (product/saliva, saliva/air) in "solid” matrices (needing mastication) [8, 9]. Also, additional phenomena have to be considered: product dissolution and melting due to intraoral manipulations (chewing, saliva incorporation, warming) and the generation of a dynamic exchange interface between product and saliva.

Existing models describing aroma release from solid food are not complete since they do not take breathing into account $[5,10]$. Furthermore, the assumptions used are not always 
transferable to other types of food matrices and to associated food oral processes than those studied (e.g. candy) or to other consumption patterns (e.g. sucking mechanism studied by Wright et al. [5]).

Hills and Harrison [10] also highlighted the importance of modelling the variation in the contact surface between the product and saliva, whose change in time plays a central role in the aroma compounds release. In their model, they suggest a multi-fragmentation theory to represent the chewing of a candy (assimilated to a cube). This approach provides a law of time change in the contact surface between product and saliva, using only two parameters: the number of bites and the duration of chewing. One might expect, however, that chewing real products, like cheeses for instance, will not always produce cubes and multiply the area by a factor of 2 after each bite. Other studies have also investigated the fragmentation of solids placed in the mouth under the action of chewing. The degree of fragmentation of a food can be determined by different types of experimental measurements such as the analysis of particle size distribution in the bolus [11]. These experimental data allow the determination of the laws of fragmentation depending on the type of food: deterministic analytic laws of product fragmentation over time [12], or probabilistic laws [8, 13-15]. While these approaches can be very comprehensive, they have several limitations. For example, some of them require complex experimental protocols that are difficult to implement (bolus spitting after a variable number of bites). Other approaches need the determination of many parameters (such as the number of chews, the number or the size of food particles after each chew, etc...), usually unknown, and which may depend on the product and/or on the individual.

From this literature review, it appears that modelling the release of aroma compounds during solid food consumption remains a challenging task and that the results of published studies are difficult to extrapolate to other experimental conditions. In this context, the present study proposes a model simulating the release of aroma compounds, applicable to different food 
matrices and different individuals with a wide range of physiological characteristics. With this

109 mechanistic model, our main objective was to understand the mechanisms and parameters governing the release of aroma compounds during the intra-oral manipulation and swallowing

111 of "solid" food (needing chewing). To do so, simulations issued from the model were

112 compared to in vivo release data of two aroma compounds, measured by atmospheric pressure

113 chemical ionization mass spectrometry (APCI-MS) on ten panelists, during the consumption

114 of four sorts of cheese, varying in composition and texture. Model assumptions are presented 115 and their validity is discussed.

\section{Mathematical modelling of in vivo aroma compound release}

\subsection{Principles of the model}

118 The aroma release model described in this study applies to food products requiring

119 mastication. It is an extension of the model developed for liquid and semi-liquid foods by

120 Doyennette et al. [7]. The new insight is the consideration of the mastication process. The

121 global eating process involves several steps shown in figure 1: the initial state of the system

122 (product introduction in mouth), the intra-oral manipulation of the product, which consists in

123 several masticatory cycles, one or more swallowing events and the resting phase (release

124 during the post-mastication stage) which occurs when there is no more product in the mouth.

125 The intra-oral manipulation phase usually lasts until the first swallow. However, in some

126 cases (particularly for firm products), it can extend beyond the first swallow.

127 Similarly to the model of Doyennette et al. [7], the present description of the swallowing step

128 includes simultaneous contractions of the oral cavity and of the pharynx, leading to air and

129 product expulsion, followed by relaxation and filling with fresh air. This will cause the 130 expulsion of the bolus formed in the mouth into the pharynx. Each swallowing step leads to 131 the deposit of a small part of the in-mouth liquid phase of the bolus on the pharyngeal walls. 
132 A residual amount of the solid part of the bolus remains in the mouth and is chewed again and

133 mixed with saliva in order to form a new food bolus suitable for swallowing.

134 A schematic representation of the four compartments involved in the model design, as well as

135 their connections and the mechanisms responsible for flavour release, are given in figure 2.

136 All variables and parameters of the interconnected compartments required for the model

137 simulation are specified in this figure.

138 Compared to the previous model [7], two main differences can be observed: first, the presence 139 of three instead of two sub-compartments in the mouth (the non-dissolved food product,

140 which is the solid part of the bolus, the liquid phase of the bolus, made of saliva and dissolved

141 food product and the air phase) and secondly, the opening of the velopharynx during chewing,

142 allowing the transport of aroma compounds between the air phases of mouth and pharynx

143 (figure 2).

144 Concerning the food bolus fragmentation under mastication, the particle size distribution in

145 the bolus after each bite has already been described in literature [8, 11, 13-15]. However, 146 these approaches require the knowledge of parameters such as food particle size after each 147 chew, which is difficult to determine experimentally, particularly for pasty products like 148 cheese used in the present study. The relevant parameter for aroma compound release is not 149 the particle size itself, but the contact area between the solid and the liquid phase of the bolus.

150 In this study, we focus on the generation of this area, as previously done in literature [16]. In

151 the following paragraphs, the main differences with the previously published model for liquid 152 products [7] are emphasized.

153 2.2.Mathematical description of mass transfer in mouth during the eating of masticated foods

154 The solid food product placed in the mouth is broken down during intra-oral manipulation.

155 Two concurrent phenomena can occur: 
- the transfer of aroma compounds from the non-dissolved product into the liquid phase of the

157 bolus,

158 - the melting (dissolution) of the product in the liquid phase of the bolus due to the combined

159 action of the mastication, the saliva incorporation and the warming of the product in the

160 mouth. This also leads to the release of aroma compounds contained in the dissolved product

161 towards the liquid phase of the bolus.

162 In practice, it is very difficult to distinguish between the relative contributions of each mechanism. Moreover, the phenomena of transfer and of dissolution can be described by very similar equations. Considering the studied products (cheeses), we arbitrarily chose to assign the release of aroma compounds into saliva to a single mechanism (dissolution) while being aware that the transfer also contributes to this process.

Similarly to Doyennette et al. [7], the transfer resistance on the air side $1 / k_{O A}$ was assumed to

169 be negligible when compared to the transfer resistance on the product side $1 / k_{O L}$ (the orders 170 of magnitude of the mass transfer coefficients, representing the reciprocal of the resistances,

171 are $10^{-2}$ and $10^{-6} \mathrm{~m} / \mathrm{s}$ respectively [17].

172 Therefore, the interfacial aroma compound concentration on the liquid bolus side, using the 173 partition conditions at the interface, is given by:

$174 \quad C_{O A L}^{*}(t)=\frac{C_{O A}(t)}{K_{O A L}(t)}$

175 The volatile mass flux between the air and the liquid bolus in the oral cavity $\phi_{O A L}$ is mainly

176 determined by the resistance located on the bolus side and is given by the difference between

177 the liquid bolus concentration $\left(C_{O L}\right)$ and the interfacial concentration $\left(C^{*}{ }{ }\right)$ :

$\phi_{O A L}(t)=k_{O L}(t) \times A_{O A L}(t) \times\left(C_{O L}(t)-C_{O A L}^{*}(t)\right)$ 
180 In addition to the aroma compound flux from the liquid bolus, the air in the mouth can also

181 exchange aroma compounds with the air in the pharynx. Jaw movements during mastication

182 induce velopharynx opening and cyclic air flow between the pharynx and the mouth [18].

183 The variation of aroma concentration in the air in the oral cavity $C_{O A}$ is thus due to the

184 volatile flux from the liquid food bolus and from the air coming from the pharynx $\left(Q_{O A} \geq 0\right.$

185 means that the air flows in the direction shown by the arrow in figure 2):

$$
V_{O A}(t) \times \frac{d C_{O A}(t)}{d t}=\phi_{O A L}(t)+ \begin{cases}Q_{O A}(t) \times\left(C_{F A}(t)-C_{O A}(t)\right) & \text { if } Q_{O A}(t) \geq 0 \\ 0 & \text { if } Q_{O A}(t)<0\end{cases}
$$

187 Little is known on the real change in $V_{O A}$. It was assumed that the masticatory movements

188 create a cyclic variation of the air volume $V_{O A}$ around a mean value $V_{O A \text { mean }}$ as it has been 189 observed by Matsuo et al. [18]. In this case:

$V_{O A}(t)=V_{O A \text { mean }}+\Delta V_{O A} \times \sin \left(2 \times \pi \times f r_{\text {opening }} \times t\right)$

191 Therefore, the air flow rate coming from the mouth $Q_{O A}$ is calculated as follows:

$Q_{O A}(t)=\frac{d V_{O A}(t)}{d t}=2 \times \pi \times f r_{\text {opening }} \times \Delta V_{O A} \times \cos \left(2 \times \pi \times f r_{\text {opening }} \times t\right)$

193 It is expected that $\Delta V_{O A}$ can be highly variable among individuals, but no quantitative data was

194 found in the literature. A fair estimation of $\Delta V_{O A}$ seems to be $20 \%$ of $V_{O A \text { mean }}$, value which

195 was used in our model. Based on observations from Matsuo et al. [18], we assumed that $196 f r_{\text {opening }}$ can vary among individuals, within a defined range. We supposed that the highest opening frequency was coordinated with the masticatory frequency ( $\left.f r_{\text {masticatory }}\right)$, and that the

198 lowest opening frequency was coordinated with the respiratory frequency $\left(F_{R}\right)$. This 199 assumption will be further discussed in the results and discussion section.

$200 \quad$ 2.2.3. Product in the oral cavity

201 In line with the assumption of the dissolution rather than transfer mechanism discussed above, 202 the aroma compound concentration in the solid (undissolved) food product fraction remains 203 constant in time: 
205 Due to dissolution and fragmentation processes, the volume of the solid food product 206 decreases over time, while its contact area with the liquid phase of the bolus increases and 207 then abruptly decreases due to swallowing.

208 The dissolution of the product at a rate $v$ gives the following equation:

$209 \frac{d V_{O P}(t)}{d t}=-v \times A_{O L P}(t)$

210 Due to fragmentation induced by mastication, the contact area between the solid product 211 present in the mouth and the liquid bolus increases in time. The exact rate of change of this 212 contact area is not known for pasty products, like cheeses used in this study. In absence of 213 more detailed information we assumed that, as long as some solid product is present in the 214 mouth and a regular mastication behaviour were considered, its contact area with the liquid 215 bolus evolves linearly over time. This simplifying hypothesis might be refined in the future 216 based on more detailed studies, however. With this assumption:

$217 \quad \frac{d A_{O L P}(t)}{d t}=\left\{\begin{array}{cl}\frac{A_{O L P d e g}-A_{O L P i n i}}{t_{d e g}-t_{0}} & \text { if } V_{O P}(\boldsymbol{t})>\mathbf{0} \\ 0 & \text { if } V_{O P}(\boldsymbol{t})=\mathbf{0}\end{array}\right.$

218 with the index "deg" meaning "at the current deglutition moment", and the index "ini" 219 meaning “at food product introduction in mouth" (at $t_{0}$ ) or "just after the previous 220 deglutition”.

221 2.2.4. Liquid bolus in the oral cavity

222 The liquid bolus compartment has a composition which evolves over time. It is initially 223 composed of pure saliva, and is progressively flavoured by the addition of dissolved product. 224 Its volume increases with the addition of saliva (salivary flow) and with the incorporation of 225 dissolved product, and periodically decreases after swallowing.

226 The volume of the bolus $V_{O L}(t)$ can be thus divided into two parts:

$227 \quad V_{O L}(t)=V_{O S}(t)+V_{O P D}(t)$ 
In that case, we have:

$229 \quad \frac{d V_{O S}(t)}{d t}=Q_{O S}$

230 with $\frac{d V_{O P D}(t)}{d t}$ the product dissolution rate, defined as

$231 \quad \frac{d V_{O P D}(t)}{d t}=v \times A_{O L P}(t)$

232 The mass balance for a given aroma compound in the bolus leads to the following equation:

$233 \quad \frac{d V_{O L}(t) \times C_{O L}(t)}{d t}=\phi_{O L P}(t)-\phi_{O A L}(t)$

234 with the volatile mass flux $\phi_{\text {OLP }}$ coming from product dissolution:

$235 \phi_{O L P}(t)=v \times A_{O L P}(t) \times C_{O P}(t)$

236 The mass flux $\phi_{\mathrm{OAL}}$ is given by the difference between the aroma concentration in the liquid

237 phase of the bolus $\left(C_{O L}\right)$ and the interfacial concentration $\left(C^{*}{ }_{O A L}\right)(E q .2)$.

238 The properties of the liquid bolus relevant for aroma compound transfer, namely the air/bolus

239 partition coefficient ( $K_{O A L}$, Eq. 1) and the mass transfer coefficient ( $k_{O L}$, Eq. 2$)$ change with

240 the relative fraction of the saliva and dissolved product in the liquid bolus. This dependence

241 was previously established [19] and included in the model simulations.

242 2.3.Mathematical description of aroma release during the pharyngeal step

243 2.3.1. Bolus in the pharynx

244 Phenomena governing flavour release from the bolus in the pharynx are similar to the ones 245 described for liquid products [7].

$246 \quad$ 2.3.2. Air in the pharynx

247 The air in the pharynx exchanges aroma compounds with the bolus in the pharynx, and with

248 the other compartments: the mouth (air flow $Q_{O A}(t)$ ), the nose (air flow $Q_{N A}(t)$ ) and the 249 trachea (air flow $Q_{T A}(t)$ ). Compared to the model of Doyennette et al. [7], air flows to and 250 from the mouth have been modified (due to the velopharynx opening during mastication). By 
convention, the air flow rates indicated in figure 2 are positive if they follow the direction of

252 the arrow. The air balance in the pharynx at any time gives the following relationship:

253

$Q_{N A}(t)=-Q_{T A}(t)+Q_{O A}(t)$

254 For the considered aroma compound, the mass balance in the air of the pharynx gives the 255 equation:

$V_{F A} \times \frac{d C_{F A}(t)}{d t}=\phi_{F A L}(t)+ \begin{cases}-Q_{O A}(t) \times\left(C_{O A}(t)-C_{F A}(t)\right) & \text { if } Q_{O A}(t)<0 \\ Q_{N A}(t) \times\left(C_{N A}(t)-C_{F A}(t)\right) & \text { if } Q_{N A}(t) \geq 0 \\ Q_{T A}(t) \times\left(C_{T A}(t)-C_{F A}(t)\right) & \text { if } Q_{T A}(t) \geq 0\end{cases}$

2.4.Conditions of the system after each deglutition

258 The deglutition step is very short compared to product residence time in mouth. It is thus 259 described as quick contraction and relaxation events (figure 1).

261 Aroma compound concentrations in the product and in the bolus are unchanged during 262 deglutition. The volume of product in the oral cavity just after deglutition $\left(V_{\text {OPdeg+ }^{+}}\right)$decreases 263 and corresponds to the volume of product just before swallowing $\left(V_{\text {OPdeg- }}\right)$ multiplied by the

264 fraction of liquid bolus remaining in the mouth after deglutition $\left(r_{L}\right)$, i.e. :

$265 \quad \mathrm{~V}_{\text {OPdeg+ }}=\mathrm{V}_{\text {OPdeg- }} \times \mathrm{r}_{\mathrm{L}}$

266 Similarly, the liquid bolus/product contact area in the oral cavity after swallowing is 267 calculated as:

$268 \quad \mathrm{~A}_{\text {OLPdeg+ }}=\mathrm{A}_{\text {OLPdeg- }} \times \mathrm{r}_{\mathrm{L}}$

270 The volumes of saliva $\left(V_{\text {OSdeg+ }}\right)$ and of dissolved product $\left(V_{\text {OPDdeg }}\right)$ in the oral cavity

271 decrease after swallowing. We assume that the bolus liquid part (saliva and dissolved product) 272 is uniformly swallowed. Therefore, we have:

$273 \mathrm{~V}_{\text {OSdeg }+}=\mathrm{V}_{\text {OSdeg- }} \times \frac{\mathrm{V}_{\text {Salivadeg }}}{\mathrm{V}_{\text {OSdeg- }}+\mathrm{V}_{\text {OPDdeg- }}}$, and $\mathrm{V}_{\text {OPDdeg }+}=\mathrm{V}_{\text {OPDdeg- }} \times \frac{\mathrm{V}_{\text {Salivadeg }+}}{\mathrm{V}_{\text {OSdeg }-}+\mathrm{V}_{\text {OPDdeg- }}}(18)$

274 with $V_{\text {Salivadeg+ }}$ being the volume of saliva usually present in the oral cavity after swallowing. 
276 To take the reservoir effect of lubricated mucosa into account, additional compartments were 277 included into the model. We assumed that air in the mouth, in the pharynx and in the nose was 278 in contact with lubricated mucosa layers within the corresponding compartment. For example, 279 in the nose, the volatile mass flux $\phi_{N A M}$ between the air and the mucosa is given by:

$\phi_{N A M}(t)=k_{N M} \times A_{N A M} \times\left(C_{N M}(t)-\frac{C_{N A}(t)}{K_{N A M}}\right)$

281 The mass balance of aroma compound in air contained in nasal cavity leads to:

$V_{N A} \times \frac{d C_{F A}(t)}{d t}=\phi_{N A M}(t)+ \begin{cases}Q_{N A}(t) \times\left(0-C_{N A}(t)\right) & \text { if } Q_{N A}(t) \geq 0 \\ Q_{T A}(t) \times\left(C_{F A}(t)-C_{T A}(t)\right) & \text { if } Q_{T A}(t) \geq 0\end{cases}$

283

and in nasal mucosa:

$V_{N M} \times \frac{d C_{N M}(t)}{d t}=-\phi_{N A M}(t)$

Here, $V_{N M}$ is the volume of lubricated mucosa which is involved in the interaction with the 286 aroma compound. It can be expressed as

$V_{N M}=e_{N M} \times A_{N A M}$

288 Similar equations were added in the mouth and in the pharynx to take the effect of the 289 lubricated mucosa present in these compartments into consideration. In the absence of more 290 detailed information, the contact area between lubricated mucosa and air was arbitrarily set to 291 half of the contact area between the bolus and the air in the mouth, as well as in the pharynx. Little information is available in the literature concerning values to be considered in the aroma retention model. The contact area between air and lubricated mucosa in the nose $A_{N A M}$ was set to $160 \mathrm{~cm}^{2}$ [20]. In literature, values comprised between $5.6 \times 10^{-5}$ and $4.8 \times 10^{-1}$ were 295 mentioned for air/mucus partition coefficient of butanol and octanol in bullfrog [21]. Thus, a 296 typical value of $1 \times 10^{-3}$ was selected here. Concerning the mucosa layer thickness, Shojaei 297 [22] gave values between 500 and $800 \mu \mathrm{m}$ in mouth and 100 to $200 \mu \mathrm{m}$ for the gingival mucosa. It is expected, however, that the aroma compound will not necessarily have time to 
diffuse in the whole epithelium thickness, and these values are considered as upper limits for

300 mucosa layer thickness involved in aroma retention.

\section{Material and Methods}

3.1. Flavoured cheese products

303 Four industrial cheese products (melt-cheese technology) varying in composition and texture

304 (two fat levels and two firmness levels) and flavoured with ethyl propanoate and 2-nonanone 305 were studied [23]. They were coded according to their characteristics, with a combination of 306 letters as following: S or F for Soft or Firm respectively and $\mathrm{l}$ or h for low-fat or high-fat 307 respectively.

308 Panelist selection and their physiological characterization at rest

309 Ten individuals were selected from a large panel composed of 44 subjects: they were verified 310 to be representative of the whole panel (mean and standard deviation) concerning 311 physiological data, masticatory behavior and APCI-MS release kinetics [23].

312 The volumes of oral, nasal and pharyngeal cavities of subjects were measured with the 313 Eccovision Acoustic Rhinopharyngometer from Eccovision (Sleep Group Solutions, North 314 Miami Beach, FL 33162). A software was developed to calculate automatically the 315 air/product areas of oral and pharyngeal cavities for each individual [7].

316 The tidal volume of each individual was measured with a spirometer (Pulmo System II, MSR, 317 Rungis, France) [23]. The respiratory frequency $F_{R}$ used in the model was calculated directly 318 from the acetone signal measured by APCI-MS.

319 3.2. In-nose measurements of aroma release by Atmospheric Pressure Chemical IonizationMass Spectrometry (APCI-MS) and data processing

321 Aroma release was measured using APCI-MS [23]. For each product, each panelist and for 322 the three replicates, a mean curve and an envelope curve (representing the standard deviation 323 of the replicates) were determined based on the peak lines (curve linking the maxima of 
aroma release profile ) [7]. Release kinetics were divided in two different phases: "phase 1"

325 corresponded to the chewing phase before the first deglutition and "phase 2" corresponded to

326 the rest of the chewing phase (if present) and to the resting phase. The end of phase 2 was set

327 when less than $10 \%$ of the maximal intensity was reached. Areas under curve (AUC) were

328 determined for each phase.

329 3.3. Physiological characterization of individuals during cheese consumption

330 Chewing activity, bolus saliva content and mouth coating were determined for each panelist 331 as described in Repoux et al. [23].

332 It has been demonstrated from various studies [24, 25] that salivary flow during food 333 consumption is much higher than the salivary flow at rest or artificially stimulated. Therefore, 334 an average rate of saliva incorporation in the bolus during food product consumption (Qos) 335 was estimated with the following equation:

$Q_{O S}=\frac{\text { percentage of incorporated saliva } \times \text { amount of food ingested }}{100 \times \text { duration of phase } 1}$

337 with the amount of food ingested $=6 \mathrm{~g}$, and phase 1 being the chewing phase before the first 338 swallow. The percentage of incorporated saliva (relative to the product) was calculated as 339 follows, based on moisture content of the initial cheese and of the bolus:

percentage of incorporated saliva $=\frac{H M_{\text {bolus }}}{100-H M_{\text {bolus }}} \times\left(100-H M_{\text {cheese }}\right)-H M_{\text {cheese }}$

341 The percentage of incorporated saliva and the duration of phase 1 were determined during two 342 separate experimental sessions, which can induce biased calculation (the salivary flow rate is 343 known to vary daily and with the physiological state of the individual). Therefore, the average 344 rate of saliva incorporation in the bolus during food consumption calculated with Eq. 23 was 345 only indicative and we preferred to use this parameter as a degree of freedom of the model for 346 simulations.

347 In this study, neither the frequency nor the displacement amplitude of the soft palate during 348 food consumption could be experimentally measured in a non-invasive way. Due to the 
uncertainty on the actual values of these parameters and to the fact that they have a similar

350 effect on the air flow rate (Eq. 5), the volume variation of the oral cavity during the consumption of cheese was arbitrarily fixed to a reference value of $20 \%$ of the mean volume and the opening frequency of the velopharynx was a degree of freedom of the model.

The contact area between the liquid bolus and the product just before swallowing $\left(A_{\text {OLPdeglu }}\right)$

354 was calculated with the assumption of spherical particles:

$\mathrm{A}_{\text {OLPdeglu }}=\frac{3 \times \mathrm{V}_{\text {OPini }}}{\mathrm{R}}$

356 The particle radius $\mathrm{R}$ was estimated with a compression device designed by the Laboratoire de Rhéologie (Grenoble, FRANCE) [26].

The modification of the air/bolus partition coefficients of ethyl propanoate and 2-nonanone,

360 due to modification of the bolus composition, was determined by the static phase ratio variation method (PRV) [27]. The mass transfer coefficients of aroma compounds into the

362 bolus were obtained by non-linear regression from dynamic headspace experiments performed with Proton Transfer Reaction-Mass Spectrometry (PTR-MS) [7]. From those in

364 vitro measurements, the relationships describing the modifications of air/bolus partition and 365 the mass transfer coefficients of ethyl propanoate and 2-nonanone in bolus as a function of 366 cheese/saliva mass ratio were integrated into the model. The cheese/saliva mass ratio $\mathrm{r}_{\mathrm{cs}}$ used 367 in the equations is given by:

$368 \quad r_{C S}=\frac{V_{O P D}}{V_{O P D}+V_{O S}}$

369 3.5. Estimation of cheese dissolution rate in artificial saliva

370 Considering the previously mentioned assumption of product dissolution, the dissolution rate 371 was estimated from measurements of the release of ionic species into warm artificial saliva, 372 using a conductivity probe. This measurement was chosen for its simplicity and for the 373 possibility to perform on-line measurements. The release of salts is considered here as a 
374 marker of the matrix dissolution. The conductivity probe was calibrated at $35^{\circ} \mathrm{C}$, with 375 aqueous $\mathrm{NaCl}$ solutions prepared with deionised water. Concentrations were measured in $\mathrm{g} / \mathrm{L}$ $376 \mathrm{NaCl}$ equivalent. A 6g-cylinder of cheese matrix, cut with a 24-mm punch, was placed in a 377 beaker containing $400 \mathrm{ml}$ of artificial saliva (including $0.216 \mathrm{~g}$ of mucin (from porcine 378 stomach type II, SIGMA-ALDRICH) per $100 \mathrm{~g}$ ) and a magnetic stirrer. The monitoring of salt 379 release (actually all species contributing to the conductivity signal) was made during two 380 minutes using a conductivity meter (MPC HEITOLAB 350) and a probe (DCP 4). Product 381 dissolution rate was determined by nonlinear regression using Matlab 7 (Natick, MA), using 382 Eq. 27.

$383 \phi_{\text {salt }}(t)=v \times A(t) \times\left(C_{P_{\text {salt }}}-C_{S_{\text {salt }}}(t)\right)$

384 where $\phi_{\text {salt }}$ is the salt mass flux between the product and saliva, $\mathrm{A}(\mathrm{t})$ the product/saliva contact 385 area and $\mathrm{C}_{\text {Psalt }}$ and $\mathrm{C}_{\text {Ssalt }}$ the salt concentrations in the solid product and in artificial saliva respectively.

3.6. Measurements of aroma compound retention by lubricated mucosa using Proton Transfer Reaction-Mass Spectrometry (PTR-MS)

389 Flavoured solutions were prepared with mineral water (Evian), ethyl propanoate and 2390 nonanone (final concentration of $4.8 \mathrm{mg} / \mathrm{L}$ for each). $134.8 \mathrm{~cm}^{3}$ Schott vials, equipped with 391 caps fitted with two valves (Interchim SCAT or InterchimOmnifit, England), were half-filled with flavoured solutions and left at $35^{\circ} \mathrm{C}$ for $2 \mathrm{~h}$ to allow thermal equilibrium.

Five panelists were recruited for this specific measurement and were instructed to suck up a mouthful of vial headspace with a straw, to swallow it and to continue to breathe normally 395 through the nose. A minimum of three replicates was performed for each individual. During this experiment, the dynamic release of aroma compounds was measured online using Proton

397 Transfer Reaction Mass Spectrometry (PTR-MS, Ionicon Analytik, Innsbruck, Austria). The 398 PTR-MS inlet was connected to the subject's nose via a 1/16" PEEK tube maintained at $60^{\circ} \mathrm{C}$. 
399

400

401

402

403

404

405

406

407

408

409

410

411

412

413

414

415

416

417

418

419

420

421

422

423

Air was sampled from the subject's nose at a flow rate of $35 \mathrm{~cm}^{3} / \mathrm{min}$ via two inlets of a stainless nosepiece placed in both of the assessor's nostrils. The PTR-MS instrument drift tube was thermally controlled $\left(\mathrm{T}_{\text {drift }}=60^{\circ} \mathrm{C}\right)$ and operated at $\mathrm{P}_{\text {drift }}=200 \mathrm{~Pa}$ with a voltage set of $\mathrm{U}_{\text {drift }}=600 \mathrm{~V}$. Measurements were performed with the multiple ion detection mode on specific masses with a dwell time per mass of 50 ms. Ethyl propanoate and 2-nonanone were respectively monitored at $\mathrm{m} / \mathrm{z} 103$ (molecular ion) and $\mathrm{m} / \mathrm{z} 143$ (molecular ion). In addition, $\mathrm{m} / \mathrm{z} 59$ (acetone) was monitored as a breath marker and $\mathrm{m} / \mathrm{z} 21$ (signal for $\mathrm{H}_{3}{ }^{18} \mathrm{O}^{+}$) and $\mathrm{m} / \mathrm{z} 37$ (signal for water clusters $\mathrm{H}_{2} \mathrm{O}-\mathrm{H}_{3} \mathrm{O}^{+}$) were monitored to check the instrument performances and cluster ion formation.

3.7. Statistical analysis

Due to the small size and the non-normal characteristic of the dataset, classical analysis of variance was not appropriate (univariate procedure using SAS/Stat ${ }^{\circledR}$ software). Instead, Friedman tests were performed with an Excel program (available at www.Anastats.fr). Rankings of samples were then obtained by the non-parametric test of multiple comparisons (Bonferroni method, level of significance set at 5\%). For the correlation test, the Spearman test was performed, with a level of significance set at 5\% (www.Anastats.fr).

\section{Results and Discussion}

4.1. Model simulations: insights in non-measured variables and assumptions on governing mechanisms

Figure 3 shows the time variation of 9 out of the 15 model variables for the release of ethyl propanoate during consumption of the cheese matrix FFl. Values of physiological parameters were fixed to the panel mean.

The volume of product present in the mouth $\mathrm{V}_{\mathrm{OP}}$ decreases slightly during the chewing period before swallowing due to dissolution phenomenon (figure 3.a). Then, it decreases sharply at the moment of swallowing. After that, only a small product portion remains in the mouth. The 
424

425

426

427

main phenomenon responsible for product volume variations appears to be the swallowing event, the dissolution having only a minor contribution. The change in saliva volume in mouth $\mathrm{V}_{\mathrm{OS}}$ is dependent on the rate of saliva incorporation in the liquid phase of the bolus Qos (assumed constant) (figure 3.b). Therefore, the longer the chewing period before swallowing, the larger this volume is. Each swallow brings the volume of saliva in the mouth down to the baseline. The volume of product dissolved in the liquid phase of the bolus $\mathrm{V}_{\mathrm{OPD}}$ (figure 3.c) has a minor contribution in the total volume of the liquid phase of the bolus $\mathrm{V}_{\mathrm{OL}}$, compared to the volume of incorporated saliva $\mathrm{V}_{\mathrm{OS}}$.

The contact area between the solid and liquid phases of the bolus in the mouth $\mathrm{A}_{\mathrm{OLP}}$ increases rapidly before the first swallow because of product fragmentation during the chewing process (figure 3.d). Then, the contact area decreases sharply at swallowing. Its variation between secondary swallows is small, because of the small amount of product remaining in the mouth. The concentration of aroma compounds in the air in the oral cavity $\mathrm{C}_{\mathrm{OA}}$ increases until swallowing due to mass transfer from the liquid bolus to the air (figure 3.e). The velopharynx opening causes small cyclical depressions. Then, swallowing creates a renewal of air and therefore a sharp decrease in concentration. Before the first swallowing, the concentration of aroma compound in the liquid phase of the bolus $\mathrm{C}_{\mathrm{OL}}$ increases due to the supply of aroma compounds from product (figure 3.f). This increase is promoted by a large contact area between the solid product and the liquid bolus. After swallowing, little product remains in the mouth; the transfer of aroma compound to the air and saliva dilution become dominant, which explain the overall decrease in aroma compound concentration in the liquid phase of the bolus. Globally, the change in concentration of aroma compounds in the air in the oral cavity $\mathrm{C}_{\mathrm{OA}}$ follows the concentration in the liquid phase of the bolus $\mathrm{C}_{\mathrm{OL}}$. The concentration of aroma compounds in the pharyngeal deposit $\mathrm{C}_{\mathrm{FL}}$ is null during the consumption stage preceding the first swallow (figure 3.g). After swallowing, a portion of the liquid fraction of 
449 the bolus is deposited in the pharynx, which causes a sharp increase in the concentration.

450 Then, aroma compounds in the pharyngeal deposit are gradually released to the air phase.

451 During secondary swallowing events, the deposit is renewed by the food bolus coming from

452 the oral cavity. However, the new layer is already depleted in aroma compounds, which leads

453 to a general decrease in $\mathrm{C}_{\mathrm{FL}}$. The air in the pharynx $\left(\mathrm{C}_{\mathrm{FA}}\right)$ receives aroma compounds from

454 the pharyngeal deposit and from the air of the oral cavity at each velopharynx opening (minor

455 peaks observed on the curve) (figure 3.h). Overall, the kinetics of concentration in the 456 pharynx $\mathrm{C}_{\mathrm{FA}}$ follow the one in oral cavity $\mathrm{C}_{\mathrm{OA}}$, up to a dilution factor. The concentration of 457 aroma compounds in the air in the nasal cavity $\mathrm{C}_{\mathrm{NA}}$ evolves similarly to the one of the air in 458 the pharynx $\mathrm{C}_{\mathrm{FA}}$ (figure 3.i). However, each inspiration of fresh air, which is aroma-free, 459 makes the signal of the concentration in the nasal cavity $\mathrm{C}_{\mathrm{NA}}$ decrease to zero.

460 As illustrated in figure 3, modelling provided insight in the change in non measured variables. 461 An important outcome was an improved understanding of mechanisms governing aroma 462 release kinetics and of the underlying assumptions.

463 4.2.Comparison of model predictions with experimental data for ethyl propanoate

464 As no interaction with lubricated mucosa was assumed for ethyl propanoate, simulations were 465 performed using the model without lubricated mucosa compartment. To compare model 466 simulations with experimental in vivo release data for ethyl propanoate, the air flow rate 467 resulting from the frequency of velopharynx opening was adjusted to fit the simulated release 468 kinetics before the first swallowing. The rate of saliva incorporation into the food bolus was 469 also adjusted so that the simulated release kinetics after the first deglutition fitted the decay 470 phase of the experimental curve.

471 All simulations have been satisfactorily fitted to experimental data (the average error of the 472 model, for all cheeses and all individuals, was only 5.88\% \pm 2.81 ). The two unknown 
473 parameters of the model (the average rate of saliva incorporation into the bolus and the

474 frequency of velopharyngeal opening) could be estimated.

475 Figure 4 presents some comparisons of simulations and experimental data for panelists S001

476 and S101. We can observe that these two individuals present diversified consumption and 477 aroma release behaviours: for example, panellist S001 exhibits a consistently longer 478 mastication time before the first swallow than panellist S101, and both panellists have longer 479 mastication times for firm matrices, as one could expect. In spite of this diversity, the model 480 correctly described the in vivo release profiles. Some slight deviations can be noticed, as for 481 instance on figures 4.a and 4.b at about 10s and 30s respectively. A possible explanation 482 could be that individuals have more complex behaviour during food consumption than 483 currently assumed in the model; for example, the amplitude of jaw movement related to 484 parameter $\Delta V_{O A}$ in Eq. 5 may vary in the course of the mastication process. This cannot be 485 correctly represented by the model with constant values of physiological parameters. One should also bear in mind that panellists' behaviour is not fully reproducible and the greyed area in Figure 4 represents an interval of \pm 1 standard deviation of 3 replicate experiments, 488 which is statistically expected to contain less than $58 \%$ of the data.

489 The mean rate of saliva incorporation into the bolus $Q_{o s}$ (for all cheeses and all panelists), 490 experimentally determined using the percentage of saliva incorporated in the bolus and the average chewing time, is $7.88 \pm 4.39 \mathrm{~mL} / \mathrm{min}$ (figure 5 , bar $\mathrm{B}$ ). Its value remains similar to the one of $Q_{\text {os }}$ estimated by fitting simulations to experimental data $(9.00 \pm 3.65 \mathrm{~mL} / \mathrm{min}$, bar C 493 in figure 5). These values are also comparable (mean and standard deviation) to the salivary 494 flow values measured experimentally during food consumption by other authors [28-30].

495 Overall, the average rate of saliva incorporation into the bolus, either measured directly or 496 estimated by fitting simulations to experimental data, was statistically much higher than the 497 salivary flow measured with mechanical stimulation $(9.00 \pm 3.65 \mathrm{~mL} / \mathrm{min}$ vs. $2.65 \pm 0.87$ 
mL/min, bar A in Figure 5) as already observed by Gaviao et al. [25] $(7.82 \pm 4.53 \mathrm{~mL} / \mathrm{min}$ vs.

$4991.40 \pm 0.67 \mathrm{~mL} / \mathrm{min}$ ), meaning that the salivary flow obtained with a mechanical stimulus is

500

501

502

503

504

505

506

507

508

509

510

511

512

513

514

515

516

517 not representative of the actual one during product consumption.

When products are compared (table 1), it appears that the average rate of saliva incorporation into the bolus for the cheese matrix Fh (firm with a high-fat content) is statistically lower than for the others cheese matrices (2-fold factor between cheese matrix Fh and cheese matrices Sh and $\mathrm{FFl}$ ), probably due to a longest consumption duration of cheese matrix Fh, as already observed in previous studies [23]. Indeed, the rate of incorporation of saliva into the bolus can be expressed as: $Q_{o s}=\frac{\text { initial volume of saliva }}{\text { duration of consumption before swallowing }}+$ salivary flow rate, with the initial volume of saliva in mouth being the same whatever the consumption duration. If we assume that the salivary flow rate is constant during time, it follows that the longer the consumption duration, the smaller Qos will be. The presence of fat can also induce a decrease in salivary flow, as already observed during the consumption of model cheese matrices [31]. In the present study, it is likely that the low value of the average rate of saliva incorporation into the bolus for the cheese matrix Fh is the result of the two phenomena mentioned above.

\subsection{Comparison of model predictions with experimental data for 2-nonanone}

In vivo observations highlighted that ethyl propanoate and 2-nonanone exhibit quite different behavior in terms of persistence (figure 6): the release amount for 2-nonanone during phase 2 was systematically higher for all individuals and all cheese matrices than for ethyl propanaote (significant difference between the areas under curve of the two aroma compounds, Friedman and Bonferroni tests, $\mathrm{p}<0.05$, not shown). We assumed that this phenomenon was the result of an interaction between this molecule and lubricated mucosa. A specific experiment, based on swallowing of aromatized air, was performed to check this assumption (see Material and Method section). An example of standardized release curve is shown in figure 7 for one panelist. Statistical analysis confirmed that 2-nonanone (solid line) persists much longer than 
523 ethyl propanoate (dotted line) in the exhaled air. This was observed for all panelists and all

524 replicates. Measurements by PTR-MS of the in vitro release of these two molecules by 525 diluting the headspace of a vial containing the same aqueous flavoured solution excluded a 526 retention effect of the PTR-MS transfer line. All these results confirmed the existence of a 527 significant retention of the 2-nonanone by oral, pharyngeal and/or nasal lubricated mucosa. 528 This phenomenon has already been highlighted for other volatile compounds such as ethanol 529 or menthol $[4,32]$.

530 Simulations performed with the model including lubricated mucosa compartments were 531 compared to in vivo release data for 2-nonanone for cheese matrices FFl and Sl. No data was 532 available for the two others cheese matrices since 2-nonanone was not detected because of its 533 high hydrophobicity and of retention by fat. The frequency of velopharynx opening and the 534 rate of saliva incorporation into the food bolus which were previously found for ethyl 535 propanoate were kept identical. Results showed that all simulations satisfactorily fitted 536 experimental data if a mucosa layer thickness of $100 \mu \mathrm{m}$ and a transfer coefficient of $5371 \times 10^{-1} \mathrm{~cm} / \mathrm{s}$ were fixed for all individuals (figure 8 ). The average error of the model was $53813.16 \% \pm 6.80$, for the two cheese matrices tested and for the ten individuals. These results will 539 have to be refined in the future, through dedicated experiments to measure aroma compound 540 retention by lubricated mucosa.

541 4.4. Velopharynx opening

542 The results of the model fitting suggested that velopharynx opening can be different between 543 individuals. We found that in 53\% of cases, the velopharynx opening was synchronized with 544 chewing frequency; in 37\% of cases, it was synchronized with respiratory frequency and in 545 the $10 \%$ remaining cases, subjects had an intermediate behavior. Although little data is 546 available on this topic in the literature, these results are consistent with observations from 547 Matsuo et al. [18], who studied the velopharynx opening of 9 persons by videofluorography 
548 during the consumption of various foods (banana, cookie, meat). They found that the opening

549 frequency varied widely among subjects, but that the opening time was related to jaw 550 movements. A link between breathing and velopharynx movements was also highlighted.

551 4.5. Analysis of model sensitivity

552 An analysis of model sensitivity was performed to evaluate the effect of some physiological 553 or physicochemical parameters on the variation of nasal concentration with time. A standard 554 nasal concentration curve was determined using mean values for panellist characteristics. 555 Then, each parameter was multiplied or divided by a factor of two (which is representative of 556 the typical variability of physiological parameters).

557 To assess the effect of each parameter on release intensity, each simulated kinetic was scaled 558 by the maximum of the standard nasal concentration curve. Three parameters were found to 559 have a strong positive effect on release intensity: the product dissolution rate in the mouth, the 560 mass transfer coefficient of aroma compound in the bolus and the air-bolus contact area in the 561 mouth. The respiratory frequency had a significant negative effect on nasal aroma 562 concentration by increasing aroma compound removal.

563 To assess the effect of each parameter on release dynamics, independently from global 564 intensity, each simulated kinetic was scaled by its own maximum intensity. Results showed 565 that only three out of the twenty parameters of the model had a major influence on the overall 566 kinetics (results not shown): the rate of saliva incorporation into the bolus during food 567 consumption Qos, the duration of the mastication before the first swallowing and the 568 velopharynx opening (amplitude $\Delta V_{O A}$ and frequency $f r_{\text {opening }}$ ). For example, an increase in 569 the rate of saliva incorporation into the bolus during food consumption resulted in a decrease 570 in the nasal concentration after the first swallow, due to the renewal of liquid phases present 571 in the mouth and pharynx (supply of fresh saliva). These results from sensitivity analysis and 572 the high level of uncertainty and of variability among individuals for physiological parameters 
573 explained why the rate of saliva incorporation into the bolus during food consumption Qos

574 and the frequency of the velopharynx opening $f r_{\text {opening }}$ were selected as the two degrees of 575 freedom of the model.

\section{5. Conclusions}

577 In conclusion, it appears that the proposed model adequately simulated ethyl propanoate 578 release during the consumption of masticated matrices by a panel of ten individuals. The 579 estimation of the average rate of saliva incorporation into the bolus and the frequency of 580 velopharyngeal opening were in agreement with literature data. This study pointed out the 581 role of mastication on the release of aroma compounds during consumption of solid food, by 582 notably impacting the residence time of products in mouth and the opening of velopharynx 583 during product intra-oral manipulation, which ensures a continuous supply of aroma 584 compounds in the nose. Model sensitivity analysis highlighted that the parameters having a major impact on flavour release when eating a solid food product are partly different from the ones highlighted in the case of liquid or semi-liquid food [7]: in that case, the mass transfer coefficient in the bolus, the breath flow rate and the thickness of post-deglutition pharyngeal

588 residue were the three key factors governing the release of aroma compounds. Differences 589 with previous work on liquid and semi-liquid food products mainly come from the duration of 590 food residence in the mouth.

591 The release of 2-nonanone highlighted the existence of retention phenomenon of this 592 molecule by lubricated mucosa. The model successfully accounted for this phenomenon. 593 Further work could help clarifying the binding mechanisms and come up with a satisfactory 594 quantitative description of the retention phenomenon [33, 34].

595 Overall, experimental release studies combined with mechanistic modelling help gaining new 596 insight into the complex phenomena of in vivo aroma compound release during the 
597 consumption of a solid food, by understanding the relative contributions of product properties,

598 of individual characteristics and of their interactions.

599 


\begin{tabular}{|c|c|c|}
\hline Symbol & Unit & Parameter \\
\hline A & $\mathrm{cm}^{2}$ & Product/saliva contact area \\
\hline $\mathrm{A}_{\mathrm{FAL}}$ & $\mathrm{cm}^{2}$ & Air/liquid bolus contact area in the pharynx \\
\hline $\mathrm{A}_{\mathrm{OAL}}$ & $\mathrm{cm}^{2}$ & Air/ liquid bolus contact area in the oral cavity \\
\hline $\mathrm{A}_{\mathrm{NAM}}$ & $\mathrm{cm}^{2}$ & Air/lubricated mucosa contact area in the nasal cavity \\
\hline $\mathrm{A}_{\mathrm{OLP}}$ & $\mathrm{cm}^{2}$ & Liquid bolus/product contact area in the oral cavity \\
\hline $\mathrm{C}_{\mathrm{FA}}$ & $\mathrm{g} / \mathrm{cm}^{3}$ & Aroma concentration in the air in the pharynx \\
\hline $\mathrm{C}_{\mathrm{FL}}$ & $\mathrm{g} / \mathrm{cm}^{3}$ & Aroma concentration in the liquid bolus in the pharynx \\
\hline $\mathrm{C}_{\mathrm{FL}}^{*}$ & $\mathrm{~g} / \mathrm{cm}^{3}$ & Aroma concentration at the air/liquid bolus interface in the pharynx \\
\hline $\mathrm{C}_{\mathrm{NA}}$ & $\mathrm{g} / \mathrm{cm}^{3}$ & Aroma concentration in the air in the nasal cavity \\
\hline $\mathrm{C}_{\mathrm{NM}}$ & $\mathrm{g} / \mathrm{cm}^{3}$ & Aroma concentration in the lubricated mucosa in the nasal cavity \\
\hline $\mathrm{C}_{\mathrm{OA}}$ & $\mathrm{g} / \mathrm{cm}^{3}$ & Aroma concentration in the air in the oral cavity \\
\hline $\mathrm{C}^{*} \mathrm{OAL}$ & $\mathrm{g} / \mathrm{cm}^{3}$ & Aroma concentration at the air/ liquid bolus interface in the oral cavity \\
\hline $\mathrm{C}_{\mathrm{OL}}$ & $\mathrm{g} / \mathrm{cm}^{3}$ & Aroma concentration in the liquid bolus in the oral cavity \\
\hline $\mathrm{C}_{\mathrm{OP}}$ & $\mathrm{g} / \mathrm{cm}^{3}$ & Aroma concentration in the product in the oral cavity \\
\hline $\mathrm{C}_{\mathrm{P}_{\text {salt }}}$ & $\mathrm{g} / \mathrm{cm}^{3}$ & Salt concentration in the solid product \\
\hline $\mathrm{C}_{\mathrm{S}_{-} \text {salt }}$ & $\mathrm{g} / \mathrm{cm}^{3}$ & Salt concentration in artificial saliva \\
\hline $\mathrm{C}_{\mathrm{TA}}$ & $\mathrm{g} / \mathrm{cm}^{3}$ & Aroma concentration in the trachea \\
\hline $\mathrm{E}$ & $\mathrm{cm}$ & Residual bolus layer thickness in the pharynx \\
\hline $\mathrm{e}_{\mathrm{NM}}$ & $\mathrm{cm}$ & Layer thickness of the lubricated mucosa in the nasal cavity \\
\hline $\mathrm{F}_{\mathrm{R}}$ & Number of cycles/s & Respiratory frequency \\
\hline $\mathrm{fr}_{\text {masticatory }}$ & Number of chews/s & Masticatory frequency \\
\hline $\mathrm{fr}_{\text {opening }}$ & Occurrence number/s & Opening frequency of the velopharynx \\
\hline $\mathrm{HM}_{\text {bolus }}$ & $\%$ & Moisture content of the bolus \\
\hline $\mathrm{HM}_{\text {cheese }}$ & $\%$ & Moisture content of cheese product \\
\hline $\mathrm{K}_{\mathrm{FAL}}$ & & Air/ liquid bolus partition coefficient in the pharynx \\
\hline
\end{tabular}




\begin{tabular}{|c|c|c|}
\hline $\mathrm{K}_{\mathrm{NAM}}$ & & Air/ mucosa partition coefficient in the nasal cavity \\
\hline $\mathrm{K}_{\mathrm{OAL}}$ & & Air/ liquid bolus partition coefficient in the oral cavity \\
\hline $\mathrm{k}_{\mathrm{FL}}$ & $\mathrm{m} / \mathrm{s}$ & Mass transfer coefficient in the liquid bolus in the oral pharynx \\
\hline $\mathrm{k}_{\mathrm{NM}}$ & $\mathrm{m} / \mathrm{s}$ & Mass transfer coefficient in the lubricated mucosa in the nasal cavity \\
\hline $\mathrm{k}_{\mathrm{OA}}$ & $\mathrm{m} / \mathrm{s}$ & Mass transfer coefficient in the air phase in the oral cavity \\
\hline $\mathrm{k}_{\mathrm{OL}}$ & $\mathrm{m} / \mathrm{s}$ & Mass transfer coefficient in the liquid bolus in the oral cavity \\
\hline $\mathrm{R}$ & $\mathrm{m}$ & Average radius of particles in the bolus. \\
\hline$r_{L}$ & $\mathrm{~g} / \mathrm{g}$ & Mass fraction of liquid bolus remaining in the mouth after deglutition \\
\hline $\mathrm{r}_{\mathrm{cs}}$ & $\mathrm{g} / \mathrm{g}$ & Cheese/saliva mass ratio \\
\hline$t_{\text {deg }}$ & $\mathrm{s}$ & Swallowing moment \\
\hline $\mathrm{Q}_{\mathrm{NA}}$ & $\mathrm{cm}^{3} / \mathrm{s}$ & Air flow rate coming from the nasal cavity \\
\hline $\mathrm{Q}_{\mathrm{OA}}$ & $\mathrm{cm}^{3} / \mathrm{s}$ & Air flow rate coming from the oral cavity \\
\hline Qos & $\mathrm{cm}^{3} / \mathrm{s}$ & Average rate of saliva incorporation in the bolus \\
\hline $\mathrm{Q}_{\mathrm{TA}}$ & $\mathrm{cm}^{3} / \mathrm{s}$ & Air flow rate coming from the trachea \\
\hline$v$ & $\mathrm{~cm} / \mathrm{s}$ & Product dissolution rate in the saliva \\
\hline $\mathrm{V}_{\mathrm{FA}}$ & $\mathrm{cm}^{3}$ & Volume of air in the pharynx \\
\hline $\mathrm{V}_{\mathrm{FL}}$ & $\mathrm{cm}^{3}$ & Volume of liquid bolus in the pharynx \\
\hline $\mathrm{V}_{\text {lung }}$ & $\mathrm{cm}^{3}$ & Lung volume \\
\hline $\mathrm{V}_{\mathrm{NA}}$ & $\mathrm{cm}^{3}$ & Volume of air in the nasal cavity \\
\hline $\mathrm{V}_{\mathrm{NM}}$ & $\mathrm{cm}^{3}$ & Volume of lubricated mucosa in the nasal cavity \\
\hline $\mathrm{V}_{\mathrm{OA}}$ & $\mathrm{cm}^{3}$ & Volume of air in the oral cavity \\
\hline$\Delta \mathrm{V}_{\mathrm{OA}}$ & $\mathrm{cm}^{3}$ & Amplitude of mouth volume variation during mastication \\
\hline $\mathrm{V}_{\mathrm{OL}}$ & $\mathrm{cm}^{3}$ & Volume of liquid bolus in the oral cavity \\
\hline $\mathrm{V}_{\mathrm{OP}}$ & $\mathrm{cm}^{3}$ & Volume of product in the oral cavity \\
\hline $\mathrm{V}_{\mathrm{OPD}}$ & $\mathrm{cm}^{3}$ & Volume of dissolved product in the bolus of the oral cavity \\
\hline $\mathrm{V}_{\mathrm{OS}}$ & $\mathrm{cm}^{3}$ & Volume of saliva in the bolus \\
\hline
\end{tabular}




\begin{tabular}{|l|l|l|}
\hline$V_{\text {Salivadeg }+}$ & $\mathrm{cm}^{3}$ & Volume of saliva usually present in the oral cavity after swallowing \\
\hline $\mathrm{V}_{\mathrm{T}}$ & $\mathrm{cm}^{3}$ & Tidal volume \\
\hline$\phi_{\mathrm{FAL}}$ & $\mathrm{g} / \mathrm{s}$ & Volatile mass flux between the air and the liquid bolus in the pharynx \\
\hline$\phi_{\mathrm{NAM}}$ & $\mathrm{g} / \mathrm{s}$ & Cavity \\
\hline$\phi_{\mathrm{OAL}}$ & $\mathrm{g} / \mathrm{s}$ & Volatile mass flux between the air and the liquid bolus in the oral cavity \\
\hline$\phi_{\text {salt }}$ & $\mathrm{g} / \mathrm{s}$ & Salt mass flux between the product and saliva \\
\hline$\tau$ & $\mathrm{s}$ & Characteristic time of the aroma release decay \\
\hline
\end{tabular}

Remark: The solid part of the bolus consists of the non-dissolved part of the food product.

\section{Acknowledgements}

603 The authors gratefully acknowledge the French National Research Agency (ANR) project

604 “SensInMouth” for financial support.

605

606 
608 [1] Chen, J. S. Food oral processing - a review. Food Hydrocolloids, 2009, 23(1), 1-25.

609 [2] Harrison, M., B. P. Hills, J. Bakker and T. Clothier. Mathematical models of flavor release from liquid emulsions. Journal of Food Science, 1997, 62(4), 653-664.

611 [3] Overbosch, P., W. G. M. Afterof and P. G. M. Haring. Flavor release in the mouth. Food 612 Review International, 1991, 7, 137.

613 [4] Normand, V., S. Avison and A. Parker. Modeling the Kinetics of Flavour Release during 614 Drinking. Chemical. Senses, 2004, 29(3), 235-245.

615 [5] Wright, K. M. and B. P. Hills. Modelling flavour release from a chewed bolus in the 616 mouth: Part II. The release kinetics. International journal of Food Science and 617 Technology, 2003, 38(3), 361-368.

618 [6] Tréléa, I. C., S. Atlan, I. Déléris, A. Saint-Eve, M. Marin and I. Souchon. Mechanistic 619 mathematical model for in vivo aroma release during eating of semi-liquid foods. Chemical Senses, 2008, 33(2), 181-192.

621 [7] Doyennette, M., C. De Loubens, I. Déléris, I. Souchon and I. C. Tréléa. Mechanisms explaining the role of viscosity and post-deglutitive pharyngeal residue on in vivo aroma release: A combined experimental and modeling study Food Chemistry, 2011, 128(2), 380-390.

[8] Harrison, M., S. Campbell and B. P. Hills. Computer simulation of flavor release from solid foods in the mouth. Journal of Agricultural and Food Chemistry, 1998, 46(7), 2736-2743.

[9] de Roos, K. B. and K. Wolswinkel. Non-equilibrium partition model for predicting

630 [10] Hills, B. P. and M. Harrison. Two-film theory of flavour release from solids. 631 International journal of Food Science and Technology, 1995, 30, 425-436. 
632 [11] Peyron, M. A., A. Mishellany and A. Woda. Particle Size Distribution of Food Boluses 633 after Mastication of Six Natural Foods. . Journal of Dental Research, 2004, 83(7), 578$634 \quad 582$

635 [12] Tobitsuka, K., M. Miura and S. Kobayashi. Retention of a European Pear Aroma Model 636 Mixture Using Different Types of Saccharides. Journal of Agricultural and Food 637 Chemistry, 2006, 54, 5069-5076.

638 [13] Agrawal, K. R., P. W. Lucas, J. F. Prinz and I. C. Bruce. Mechanical properties of foods 639 responsible for resisting food breakdown in the human mouth. Archives of Oral Biology,

641 [14] van der Bilt, A., L. W. Olthoff, H. W. van der Glas, K. van der Weelen and F. Bosman. 642 A mathematical description of the comminution of food during mastication in man. Archives of Oral Biology, 1987, 32(8), 579-586.

644 [15] Wright, K. M. and B. P. Hills. Modelling flavour release from a chewed bolus in the 645 mouth: Part I. Mastication. International Journal of Food Science and Technology, 2003, $646 \quad 38(3), 351-360$

647 [16] de Loubens, C., M. Panouillé, A. Saint-Eve, I. Déléris, I. C. Tréléa and Souchon I. . 648 Mechanistic model of in vitro salt release from model dairy gels based on standardized 649 breakdown test simulating mastication. Journal of Food Engineering 2011, 105(1), 161$650 \quad 168$.

651 [17] Cussler, E. L. Diffusion. Mass Transfer in Fluid Systems. University Press, Cambridge, $652 \quad 1997$.

653 [18] Matsuo, K., H. Metani, K. A. Mays and J. B. Palmer. Effects of Respiration on Soft 654 Palate Movement in Feeding. Journal of Dental Research, 2010, 89, 1401-1406. 
[19] Doyennette, M., I. Déléris, A. Saint-Eve, A. Gasiglia, I. Souchon and I. C. Tréléa. The dynamics of aroma compound transfer properties in cheeses during simulated eating conditions. Food Research International, 2011, 44(10), 3174-3181.

[20] Levitzky, M. G. Pulmonary physiology, 2003.

[21] Hornung, D. E., S. L. Youngentob and M. M. Mozell. Olfactory Mucosa-Air Partitioning of Odorants. Brain Research Bulletin., 1987, 413(1), 147-154.

[22] Shojaei, A. H. Buccal mucosa as a route for systemic drug delivery: a review. Journal of Pharmaceutical Sciences, 1998, 1(1), 15-30.

[23] Repoux, M., H. Laboure, P. Courcoux, I. Andriot, E. Semon, C. Yven, G. Feron and E. Guichard. Combined effect of cheese characteristics and food oral processing on in vivo aroma release. Flavor and Fragrance Journal, 2012, 27(6), 414-423.

[24] Watanabe, S. and C. Dawes. A Comparison of the Effects of Tasting and Chewing Foods On the Flow-rate of Whole Saliva In Man. Archives of Oral Biology, 1988, 33, 761-764.

[25] Gaviao, M. B., L. Engelen and A. Van der Bilt. Chewing behavior and salivary secretion. European Journal of oral science, 2004, 112(1), 19-24.

[26] Yven, C., J. Patarin, A. Magnin, H. Labouré, M. Repoux, E. Guichard and G. Féron. Consequences of individuals chewing strategies on bolus rheological properties at the swalllowing treshold. Jourrnal of Texture Studies, 2012, 43(4), 309-318.

[27] Ettre, L. S., C. Welter and B. Kolb. Determination of gas-liquid partition coefficients by automatic equilibrium headspace-gas chromatography utilizing the phase ratio variation method. Chromatographia, 1993, 35(1/2), 73-84.

[28] Mioche, L., O. Bourdiol, S. Monier and J. F. Martin. The relationship between chewing activity and food bolus properties obtained from different meat textures. Biosciences, Biotechnology, Biochemistry, 2002, 69(9), 1669-1676. 
679 [29] Patarin, J., D. Blésès, A. Magnin, C. Yven, H. Labouré and G. Féron. Mechanical 680 characterization of cheese food bolus: a new device. Food Oral Processing congress, $681 \quad$ Leeds, U.K., 2010.

682 [30] Anderson, K., G. S. Throckmorton, P. H. Buschang and H. Hayasaki. The effects of 683 bolus hardness on masticatory kinematics. Journal of Oral Rehabilitation, 2002, 29(7), $684 \quad 689-696$.

685 [31] Tarrega, A., C. Yven, E. Sémon and C. Salles. Aroma release and chewing activity 686 during eating different model cheeses. International Dairy Journal, 2008, 18(8), 849-857.

687 [32] Van Ruth, S. M., J. Frasnelli and I. Carbonell. Volatile flavour retention in food 688 technology and during consumption: Juice and custard examples. Food Chemistry, 2008, 689 106(4), 1385-1392.

690 [33] Medinsky, A. and J. A. Bond. Sites and mechanisms for uptake of gases and vapors in 691 the respiratory tract. Toxicology, 2001, 160, 165-172.

692 [34] Kurtz, D. B., K. Zhao, D. E. Hornung and P. Scherer. Experimental and numerical 693 determination of odorant solubility in nasal and olfactory mucosa. Chemical Senses, $694 \quad$ 2004, 29(9), 763-773.

695 [35] Salles, C., M. C. Chagnon, G. Féron, E. Guichard, H. Labouré, M. Morzel, E. Sémon, A. 696 Tarrega and C. Yven. In-mouth mechanisms leading to flavor release and perception. $697 \quad$ Critical Reviews in Food Science and Nutrition, 2011.

698 
700 Figure 1. Schematic representation of the chronological steps of the consumption of a solid 701 food product.

702 Figure 2. Schematic representation of the interconnected compartments and of the 703 mechanisms involved in flavour release during the consumption of a solid food product.

704 Figure 3. Time variation of 9 model variables for the release of aroma compounds during the 705 consumption of a solid product: (a) solid product volume in the mouth $V_{O P}$, (b) volume of 706 saliva in the mouth $V_{O S}$, (c) volume of dissolved product in the liquid phase of the bolus $V_{O P D}$, (d) contact area between solid and liquid phases of the bolus in the mouth $A_{O L P}$, (e) aroma compound concentration in the air of the oral cavity $C_{O A}$, (f) aroma compound concentration in the liquid phase of the bolus in the mouth $C_{O L}$, (g) aroma compound concentration in the pharyngeal deposit $C_{F L}$, (h) aroma compound concentration in the air in the pharynx $C_{F A}$ and (i) aroma compound concentration in the air in the nasal cavity $C_{N A}$. values of the physiological parameters. Time 0 corresponds to the moment of the first swallowing. Vertical lines indicate the time of product introduction in mouth and the 715 successive swallowing events.

Figure 4. Comparison of simulated and experimental release profiles for ethyl propanoate for panelists S001 (a-d) and S101 (e-h) and for cheese matrices FFl (a, e), Fh (b, f), Sl (c, g) and Sh $(d, h)$. For each figure, the simulation is represented by a thick line, the average curve of the three replicates by a thin line and the envelope curve representing the standard deviation 720 of three repetitions by the "gray" area. The characteristic moments of consumption (product 721 introduction in mouth and the successive swallowing events) are represented by vertical lines.

722 The two graphs in the form of bars at the right of the main figure present the values of two 723 parameters before and after model fitting. The initial value is symbolized by a square and the 
724 estimated value after the adjustment of the model by a triangle. The extreme values

725 (maximum and minimum) give the physiological range of variation for each parameter 726 (extracted from the initial panel of 50 individuals).

727 Figure 5. Comparison of the average rate of saliva incorporation into the bolus estimated by 728 model fitting with literature data. A) Salivary flow rate (parafilm stimulation), B) Average 729 rate of saliva incorporation in the bolus (determined experimentally by measuring the dry 730 extract of the bolus), C) Average rate of saliva incorporation in the bolus (estimated by model 731 fitting), D) Average rate of saliva incorporation in the bolus given by [25]), E) Average rate 732 of saliva incorporation in the bolus reported in [35]) and F) Average rate of saliva 733 incorporation in the bolus reported in [24]).

734 Figure 6. Comparison of in vivo release profiles of ethyl propanoate (thin envelope curve and 735 dark gray line) and 2-nonanone (thin envelope curve and light gray line) for subject S001, 736 cheese matrix FFl. The characteristic moments of consumption (product introduction in 737 mouth and the successive swallowing events) are represented by vertical lines.

738 Figure 7. Comparison of in vivo release of ethyl propanoate (dotted line) and 2-nonanone 739 (solid line) following the ingestion of flavoured air (1 panelist, 1 replicate). The data are 740 normalized to their maximum intensity.

741 Figure 8. Comparison of simulated and experimental release profiles for 2-nonanone for 742 panelist S001 for cheese matrices (a) FFl and (b) Sl, and for panelist S101 for cheese matrices 743 (c) FFl and (d) Sl. For each figure, simulation is represented by a thick line, the average curve 744 on the three replicates by a thin line and the envelope curve representing the standard 745 deviation of three repetitions by the "gray" area. The characteristic moments of consumption 746 (product introduction in mouth and successive swallowing events) are represented by vertical 747 lines. 


\section{Table captions}

750 Table 1. Comparison of the average rates of saliva incorporation into the bolus (in $\mathrm{mL} / \mathrm{min}$ )

751 for the 4 cheese matrices. The letters indicate the classification group of the products

752 (Friedman and Bonferroni tests are significant at the level 5\%). 


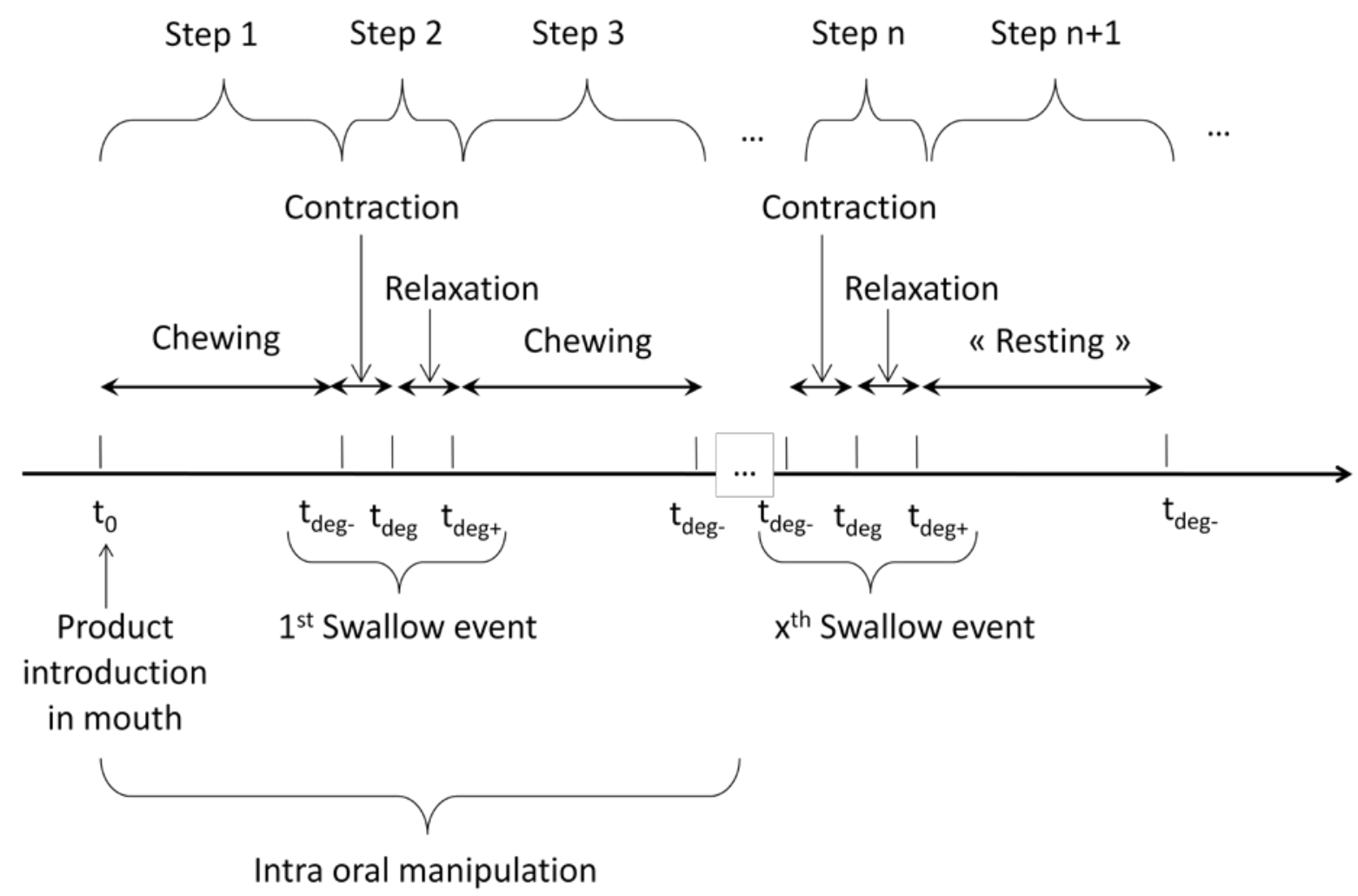

Figure 1. 


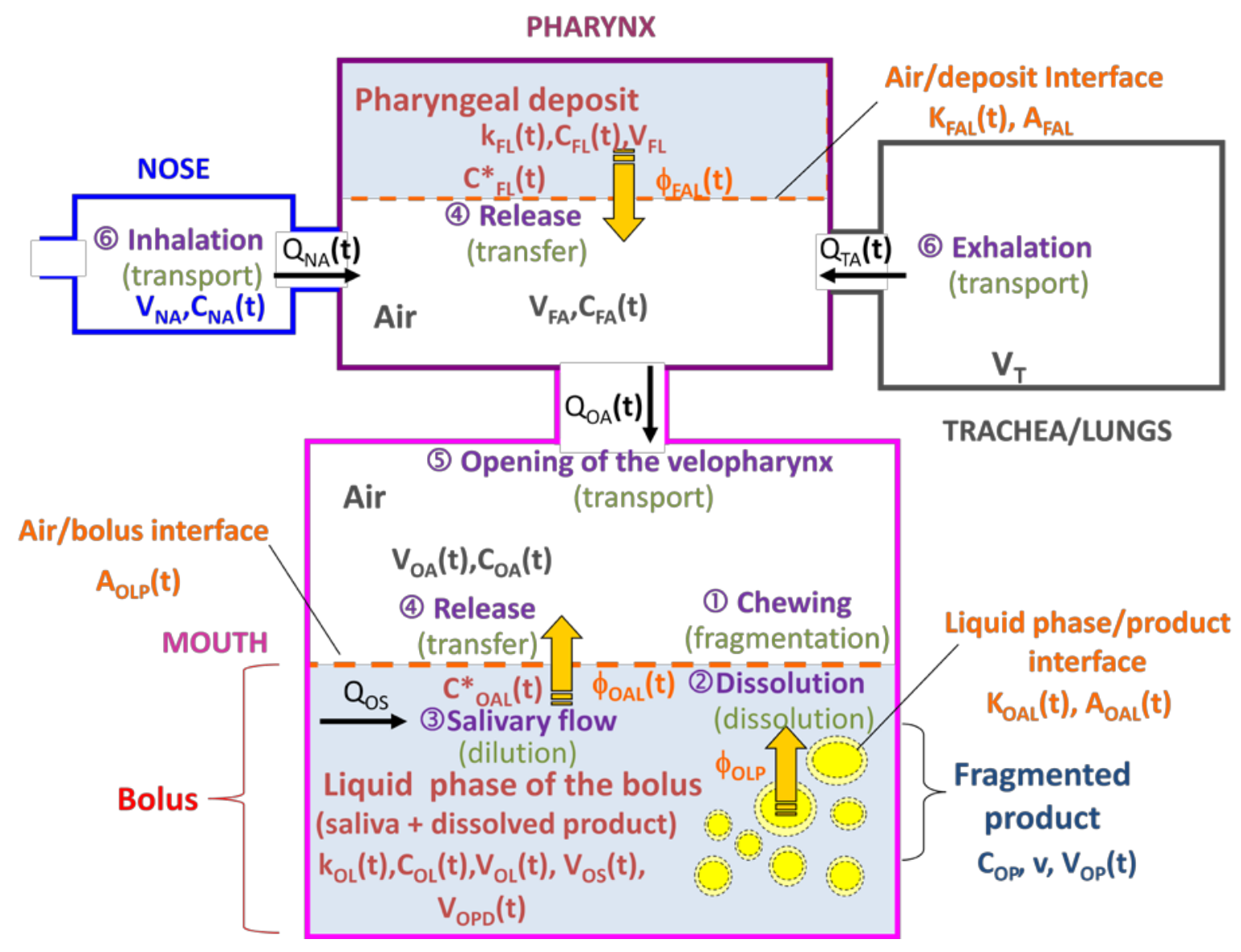

Figure 2. 

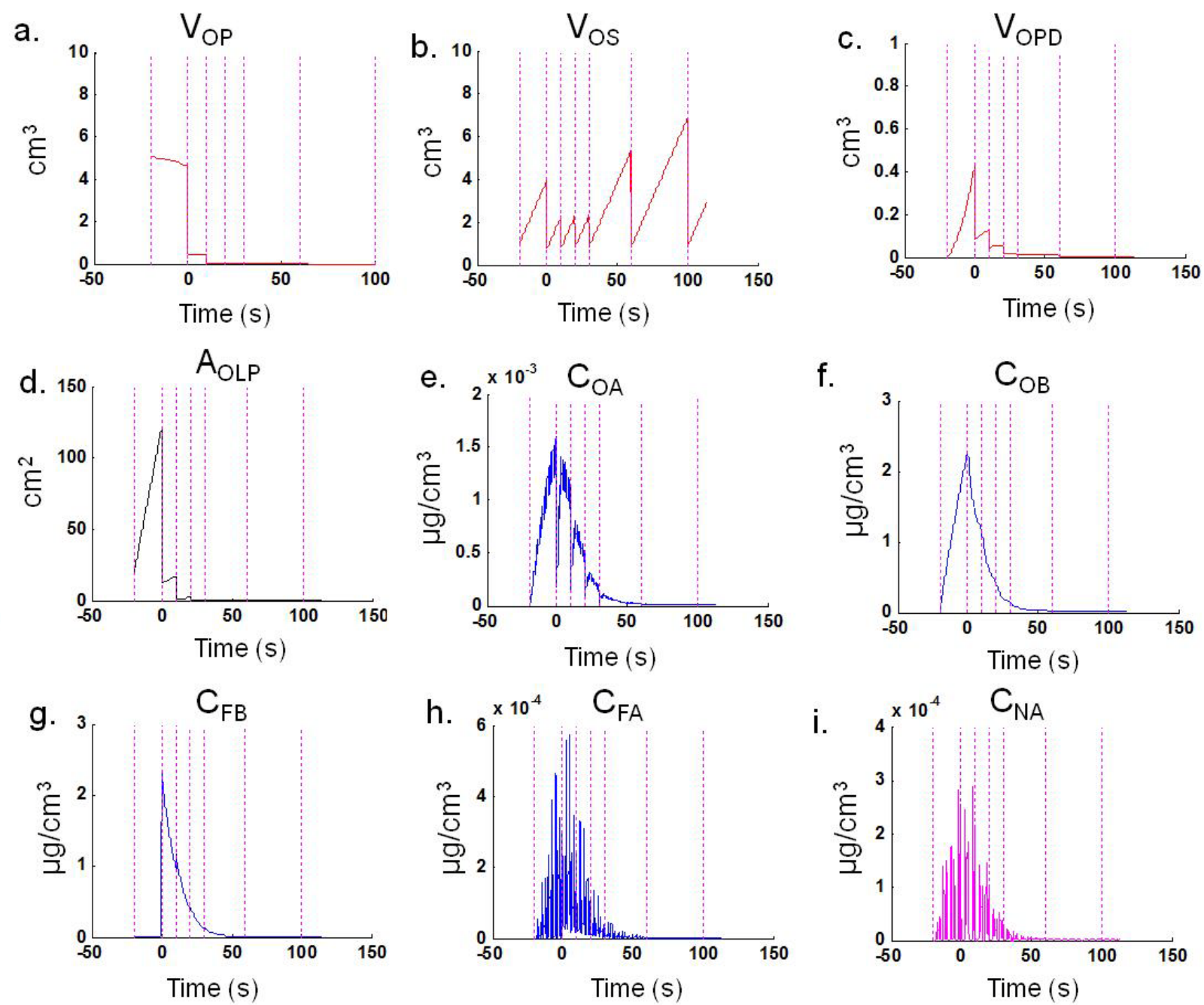

Figure 3. 


\section{Click here to download 4. Figure: Figure 4_doyennette.pdf}
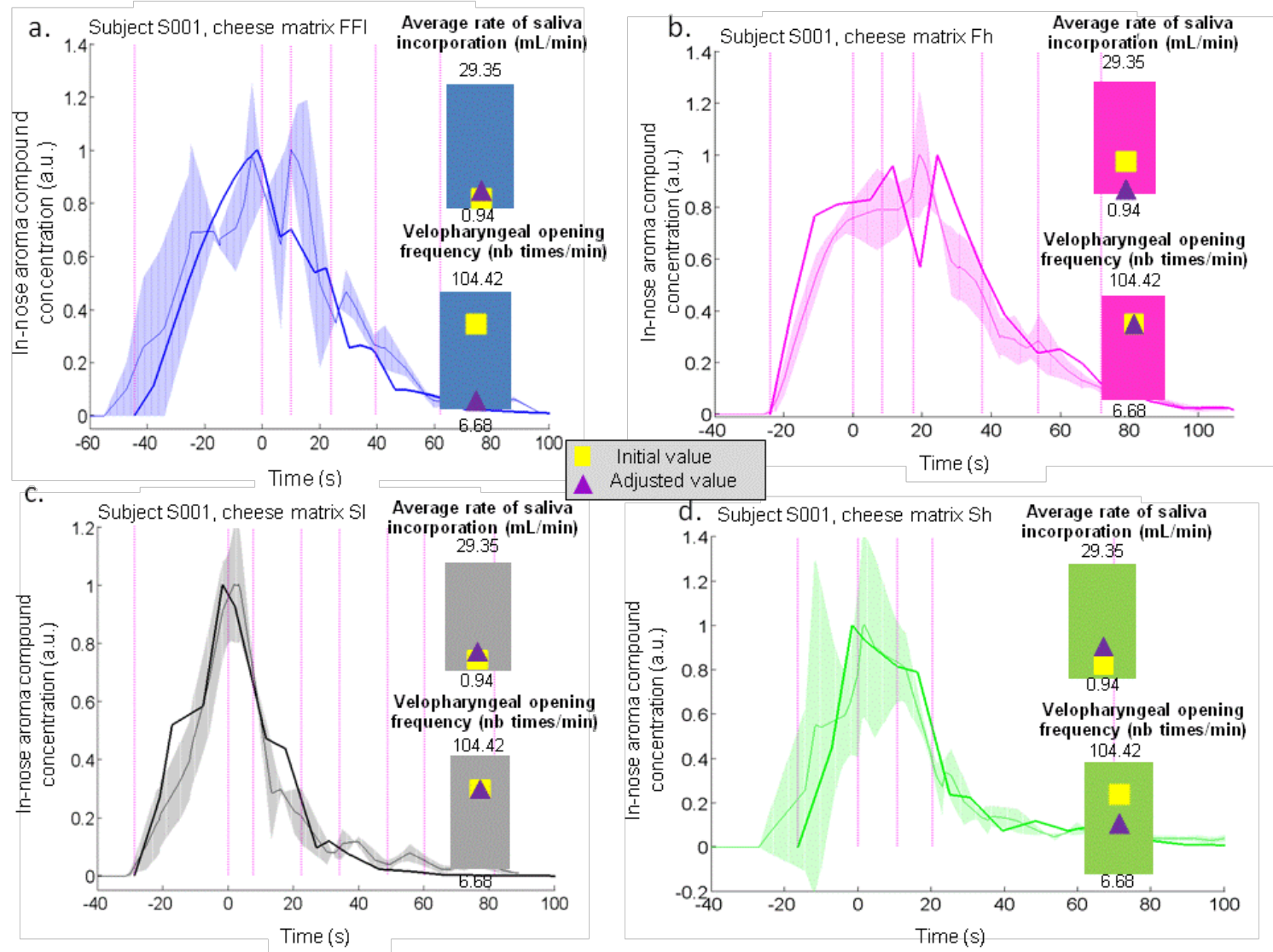

e. Subject $\mathrm{S} 101$, cheese matrix FFI Average rate of saliva
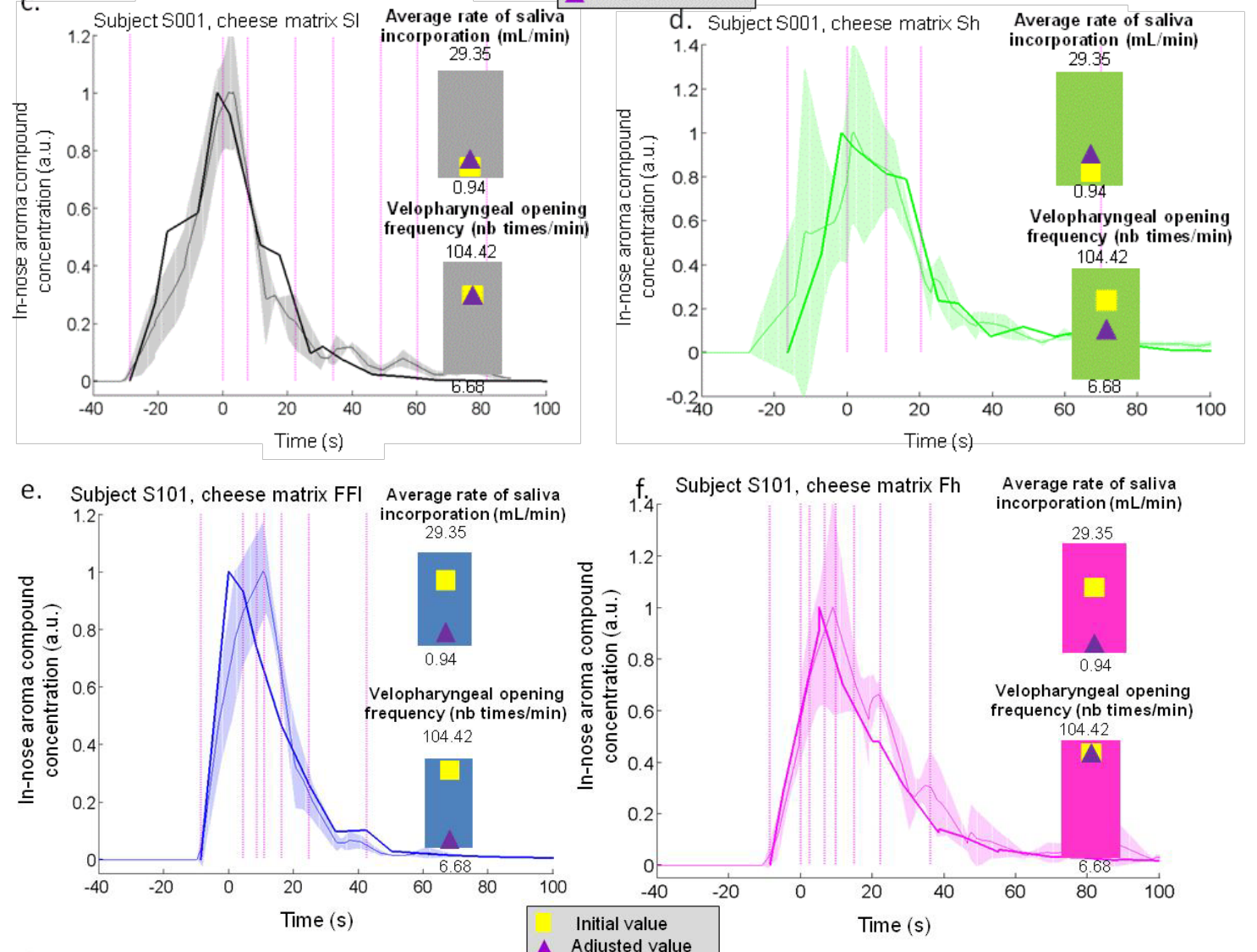

g. $\triangle$ Adjusted value
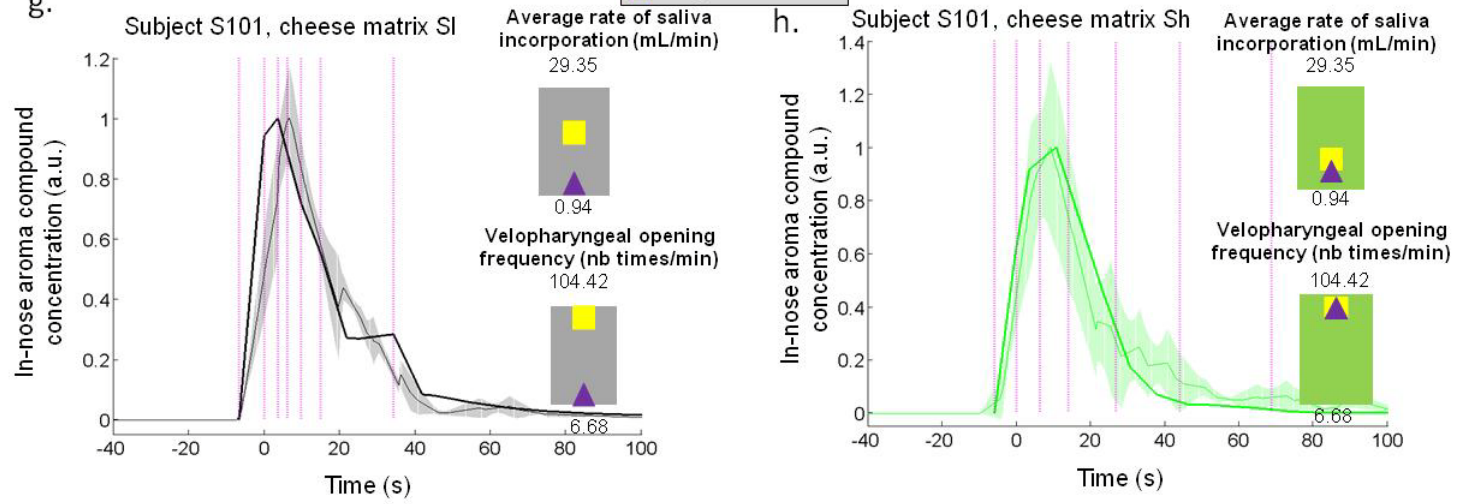

Figure 4. 


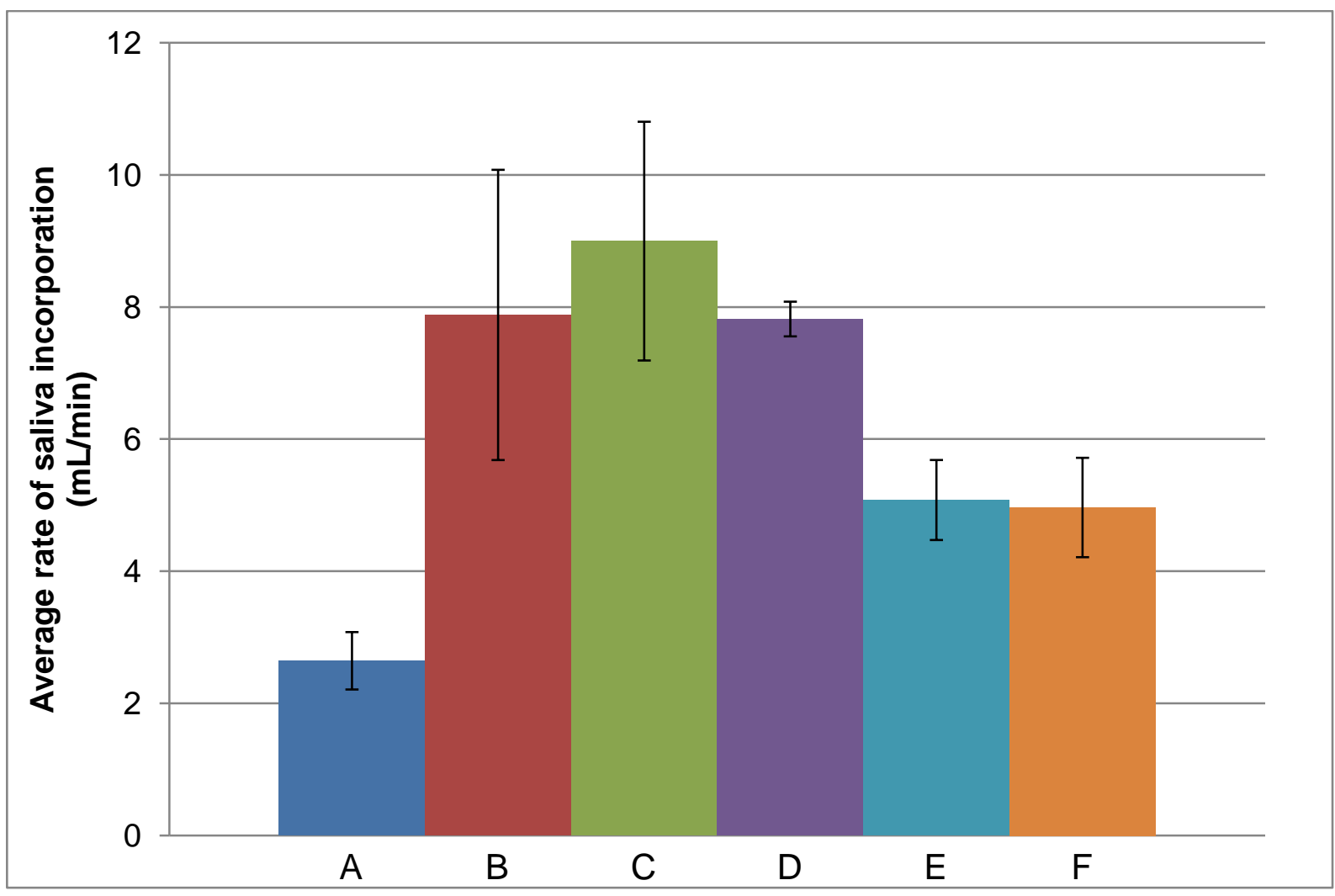

Figure 5. 
Subject S001, cheese matrix FFI

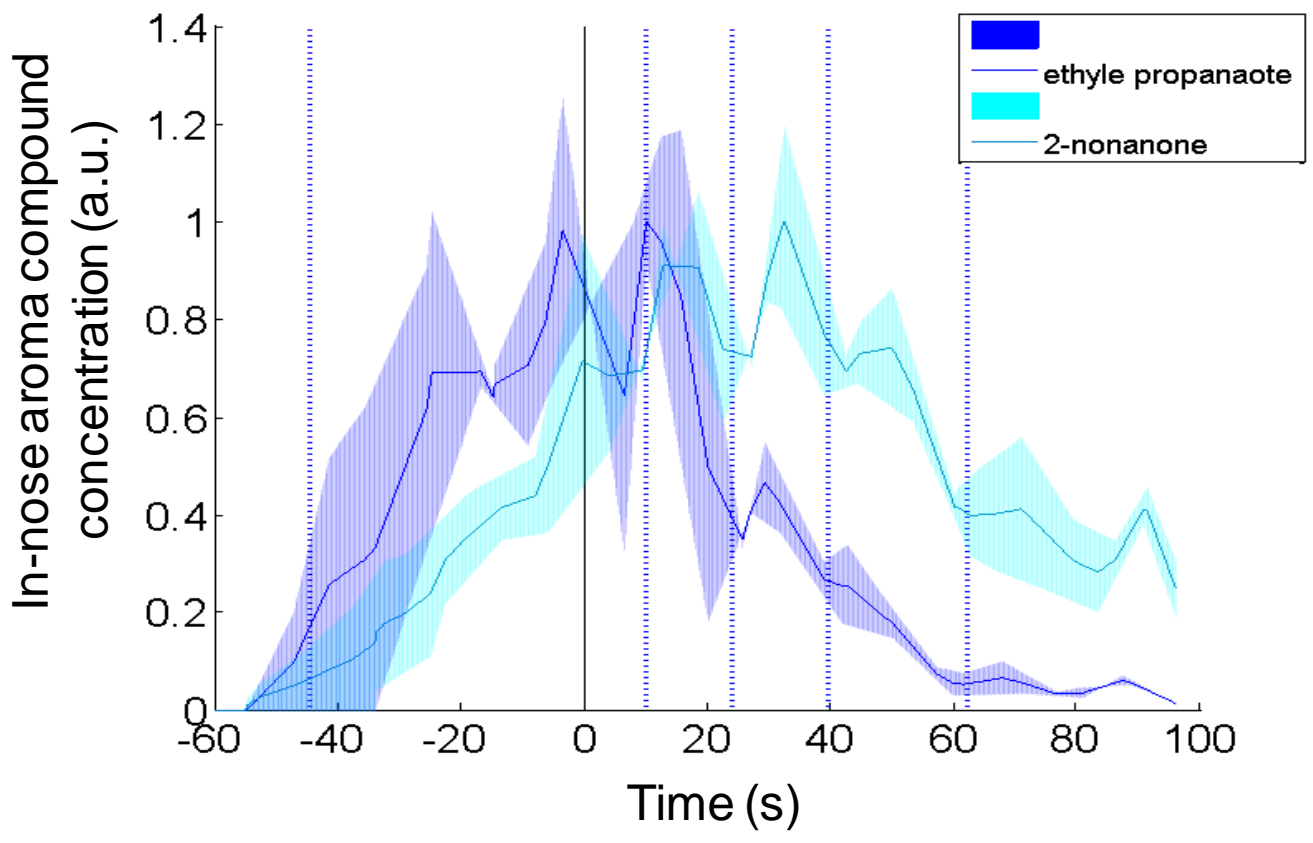

Figure 6. 


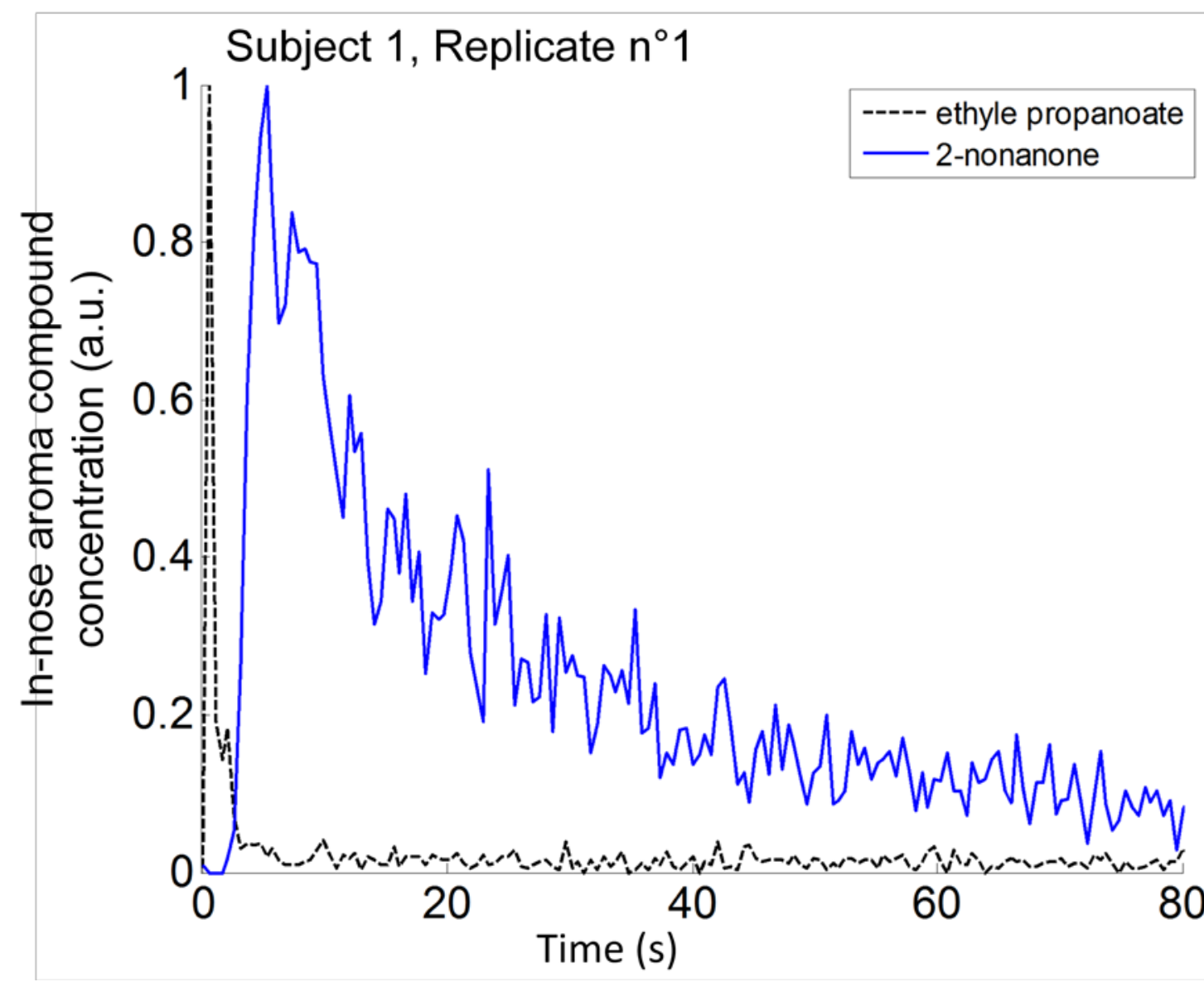

Figure 7 

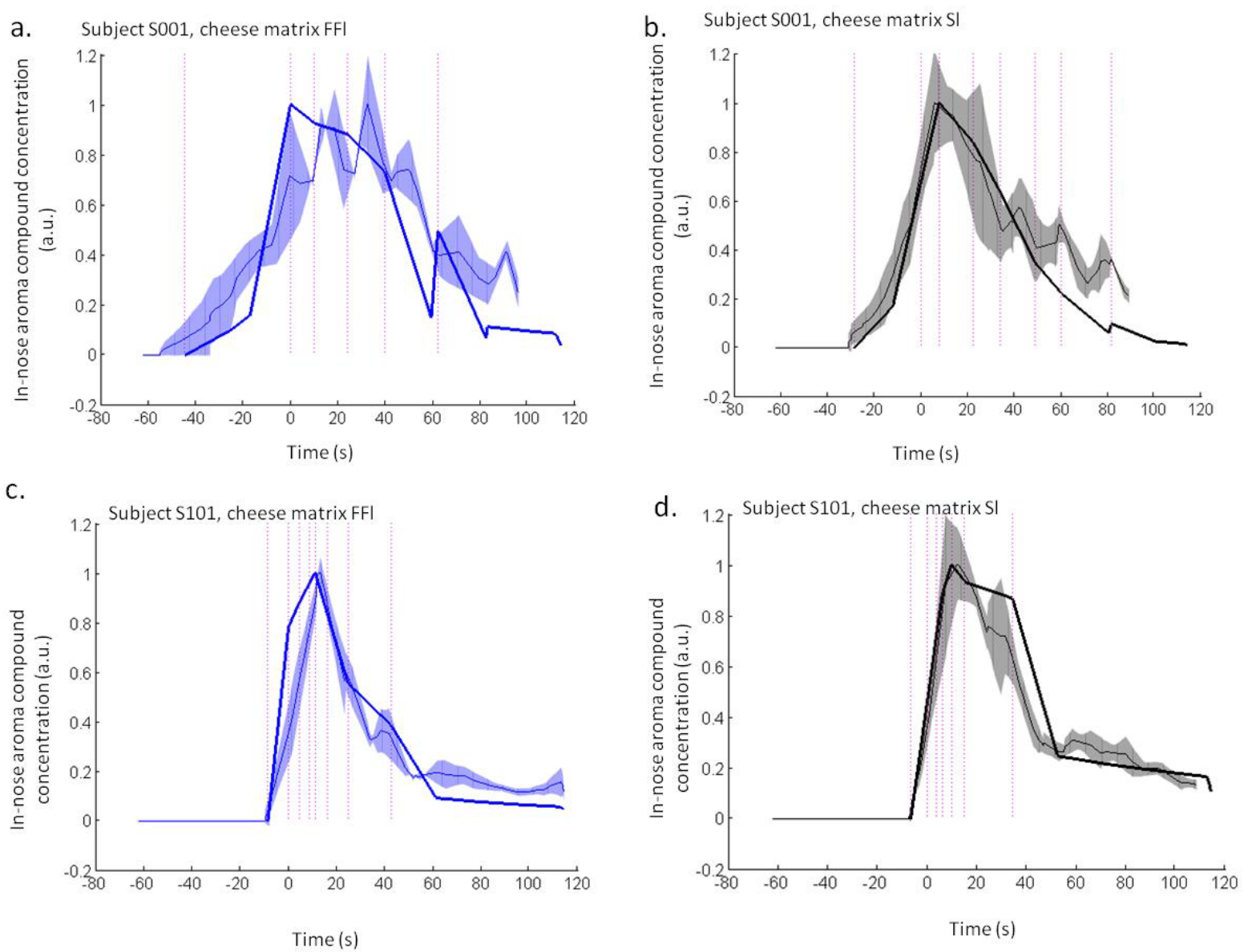

Figure 8 
Table 1.

\begin{tabular}{|c|c|c|c|c|}
\hline Rate of saliva incorporation & FFl & Sh & Sl & Fh \\
\hline Mean value (mL/min) & 10.50 & 10.80 & 9.43 & 5.27 \\
\hline Standard deviation (mL/min) & 5.70 & 4.97 & 6.16 & 8.08 \\
\hline Group & A & A & AB & B \\
\hline
\end{tabular}

